ISSN (print) o867-2008 / ISSN (online) 239 I-75 I 2

DOI: http://dx.doi.org/10.12775/OM.2019.008

Sylvain Gouguenheim*

Ecole Normale Supérieure de Lyon

16 Parvis Descartes

F-69007 Lyon

EA 1132 HISCANT-MA Université de Lorraine

France

sylvain.gouguenheim@free.fr

\title{
DAS RÄTSEL DES VERTRAGS VON LONYZ IM KERN DER AUSEINANDERSETZUNG ZWISCHEN DEM DEUTSCHEN ORDEN UND DEM BISCHOF CHRISTIAN VON PREUSSEN (1222/1240/1264)
}

\section{KEYWORDS}

history; the Middle Ages; Prussia; Christian Bishop of Prussia; Conrad Duke of Masovia; Teutonic Order; Culmerland; forgeries

\section{ABstract}

The mystery of the Lonyz Treaty (I222) at the heart of the conflict between the Teutonic Order and the Bishop of Prussia Christian

In I 222, at Lonyz, the Duke Conrad of Masovia gave to the bishop in charge of the christianization of Prussia, Christian, some goods in the Culmerland. The existence of three different versions of this treatise (confirmation by the pope in I 223 - two vidimus of I $238 /$ I 240 and I 264) has led to many debates between historians. What was the initial donation? Are later versions forgeries? And from whom? From a rereading of the documents and the study of the historical, archaeological and geographical context one arrives at the following hypothesis: the version of 1240 was interpolated by Christian of Prussia to incorporate the land of Löbau and the castles which protected this land. If Christian had indeed ceded his property in the Culmerland to the Order in I 23 I, he had retained some estates and still had rights in the land of Lubawa (agreement concluded with the Order between April I 240 and April I 242). It would not be strictly speaking of a forgery but of the insertion of legitimate elements to defend the bishop and his estates against the usurpations of the Teutonic Order. The I 264 version was simply updated by the Teutonic Order to take into account territorial changes since the late I 220 (replacement

* ORCID: https://orcid.org/0000-0003-I 89 I-694I 
of the Bishop of Prussia by four bishops, agreements with the Dukes of Masovia on the land of Löbau between I 242 and I 257 , entrance of the bishop of Culm into the Teutonic Order).

$\mathrm{D}$ as Vorhandensein von drei verschiedenen schriftlichen Überlieferungen, die mit dem Lonyzer Vertrag ( 1222 ) verbunden sind, ist einer der Bestandteile des Streits zwischen dem Deutschen Orden und dem Bischof Christian in den Jahren I 238 - I 240 (wenn auch eine dieser Fassungen von I 264 stammte). Die Möglichkeit einiger rechtmäßiger Interpolationen, oder Fälschungen, erregte die Aufmerksamkeit der Forscher und wirft ein Licht auf die Taktik der beiden Protagonisten.

I 222 gewährte Konrad, Herzog von Masowien, dem für die Christianisierung Preußens zuständigen Bischof Christian einige Besitzungen in Kulmerland. Die Region wurde in dieser Zeit von polnischen Herzögen verteidigt, die dort Land besetzten, vor allem Konrad, aber auch Henryk Brodaty, Herzog von Schlesien, und der mit dem Abkommen verbundene Bischof von Płock, Gedko. Die Vereinbarung wird von wichtigen Zeugen bestätigt, die die oberste Schicht der polnischen herrschaftlichen und kirchlichen Eliten zusammenbrachte: Herzog Leszek von Kleinpolen ( I 202-1 227), Wincenty, Erzbischof von Gniezno, die Bischöfe Iwo von Krakau ( I 2 I 8- I 229), Paweł von Poznań ( I 2 I I-I 239/ I 242), Wawrzyniec von Breslau (I 207-I 232), Wawrzyniec von Lebus ( I 209-I 233) und Michał von Kujawien (1220-I252). Der Heerzug von I 222 spiegelte den kollektiven Willen dieser Herzöge, den Kampf gegen die Prußen wieder aufzunehmen.

Das Kulmerland war damals ein Grenzgebiet zwischen Masowien und dem heidnischen Prußen; dort ließen sich Christen nieder, die ständig von den heidnischen Einfällen bedroht waren. Christian war, als „Bischof von Preußen“ (seit I 2 I 5), für seine Evangelisierung verantwortlich. Dank dieser Funktion löste er sich aus der Oberherrschaft der Kirche von Płock, deren Zuständigkeit das Kulmerland bisher unterlag.

Nach und nach erwarb dort der Bischof mehrere Gebiete. Im Februar I 2 I 6 bestätigten zwei päpstlichen Briefe die Schenkungen der Häuptlinge Survabuno und Warpoda nach ihrer Bekehrung: Survabuno und seine Söhne boten das Land Löbau (poln. Lubawa) an - ein Beweis dafür, dass die christliche Predigt aus dem Kulmerland nach Osten weitergegangen war. ${ }^{1}$ Seinerseits gab Warpoda das Land

I Preußisches Urkundenbuch. Politische (allgemeine) Abteilung, Bd. I, Die Bildung des Ordensstaats, Hälfte I, hrsg. v. Rudolf Philippi in Verbindung mit [Carl P.] Woelky (Königsberg/Pr.: Hartungsche Verlagsdruckerei, I 882), 7 Nr. 9. Gustav Liek, Die Stadt Löbau in Westpreussen, mit Berücksichtigung des Landes Löbau (Marienwerder: Im Verlage des historischen Vereins, I 892), 6-7. 
Lausania/Lansania, dessen Lage noch unklar ist. ${ }^{2}$ Für die meisten Historiker lag es in der Nähe von Löbau. ${ }^{3}$ Doch in einer Vereinbarung zwischen dem Orden und Świętopełk befindet sich das castrum Pin, bei Kulm (Chełmno), in terra que vocatur Lanzani. ${ }^{4}$ Dieses Löbauer Land stand seit dem о o. Jahrhundert in ständigem Kontakt mit slavischen und deutschen Kaufleuten. Also war es von der christlichen Welt nicht unbekannt, und Christian traf dort Menschen, die der Bekehrung weniger feindlich gesinnt waren als in nördlicheren Regionen.' Aber diese Gegend, in unmittelbarem Kontakt mit den Prußen, hatte keine vollen Sicherheitsgarantien. Der Papst ermutigte daher die polnischen Herzöge, Christian einige Besitztümer zu gewähren. Am I 8. Mai I 2 I 9 übergab ihm Konrad von Masowien possessiones und villas, wahrscheinlich im Kulmerland. ${ }^{6} \mathrm{Zu}$ einem unbekannten Zeitpunkt, um I 2 18/12 19, erhielt der Bischof das castrum Kulm und die umliegenden Besitzungen. Im April 122 I mussten sich die Kreuzritter von Polen und

2 Preußisches Urkundenbuch, I. I, hrsg. v. Philippi, 7-8 Nr. I $о$.

3 Johannes Voigt, Geschichte Preussens von den ältesten Zeiten bis zum Untergange der Herrschaft des Deutschen Ordens, Bd. I, Die Zeit des Heidentums (Königsberg: Verlag der Gebrüder Bornträger, I 827), 44I; Carl P. Woelky regte Lensk bei Lautenburg an (Carl P. Woelky, "Der Katalog der Bischöfe von Kulm," Zeitschrift für die Geschichte und Alterthumskunde Ermlands 6 (I 875-I 876 [I 877]): 363-44 I). Rudolf Philippi vermutete, Lansania sei Lensk, südostlich von Löbau (Preußisches Urkundenbuch, I. I, hrsg. v. Philippi, 7-8, Anm. 4 auf der S. 7). Gustav Liek hat Londzin/Łążyn, eine Meile von Löbau, vorgeschlagen (vgl. Liek, Die Stadt Löbau, 3 I-32). Paweł Grochowski akzeptiert neuerdings die von Tomasz Jasiński vorgeschlagene Identifizierung Lonyz mit Łońsk in Kujawien (vgl. Tomasz Jasiński, "Okoliczności nadania ziemi chełmińskiej Krzyżakom w I 228 roku w świetle dokumentu łowickiego," in Balticum. Studia z dziejów polityki, gospodarki i kultury XII-XVII wieku ofiarowane Marianowi Biskupowi $w$ siedemdziesiata rocznice urodzin, hrsg. v. Zenon H. Nowak (Toruń: Towarzystwo Naukowe w Toruniu, I 992), I 5 I- I63 hier I 5 I, Anm. I; Paweł Grochowski, Chrystian. Biskup Prus I2I6-I245 i misja pruska jego czasów (Górna Grupa: Wydawnictwo Verbinum, 20 I 8), 97).

4 Am 24. November I 248 übergab Herzog Świętopełk dem Orden in Schmiedswerder das castrum Pin: Ego Sanctopulcus, dux Pomeranie, litteris predictorum vicemagistri et fratrum, quas michi dederant super terra, que vocatur Lanzani, loco castri Pin, quamdiu viverem, possidenda, quia eas pre manibus non habebam, coram supradicto archidiacono renunciavi expresse ac promisi, me illis in posterum non usurum, vgl. Preußisches Urkundenbuch, I. I, hrsg. v. Philippi, I 38 - I 39 Nr. I94.

s G. Liek berichtet von vielen kaiserlichen und angelsächsischen Münzen aus dem I o., I I. und I 2. Jh. (Münzen, die in Köln unter den Ottonen oder Konrad II. geprägt wurden, andere mit dem Zeichen von Ethelred II. (958-975) oder Étienne de Blois ( I 35 - I I 54)), vgl. Liek, Die Stadt Löbau, 6-7.

6 Siehe die päpstliche Bestätigung: possessiones et villas, quas nobilis vir Conradus dux Mazovie, tibi et successoribus tuis pia liberalitate donavit, prout in ipsius litteris plenius continetur, auctoritate tibi apostolica confirmamus, vgl. Preußisches Urkundenbuch, I. I, hrsg. v. Philippi, 22-23 Nr. 32). 
Pommern verpflichten, ihm zu helfen.7 1222 wurde Christian für die Genehmigung belohnt, die er für die Wiederherstellung des von den Heiden zerstörten $c a$ strum Kulm erteilt hatte. In diesem Fall hielten sich die polnischen Herzöge an ein Mandat von Honorius III. vom I6. Mai I 2 1 8, das den Kreuzrittern verbot, ohne seine Zustimmung ins Land des Bischofs einzutreten. ${ }^{8}$ Christian herrschte also gleichzeitig über ein Land und eine Diözese. Das Ende des Lonyzer Vertrags zeigt es ganz klar: er hat das Recht, in der Burg Kulm (in castro Colmensi) seinen Hof einzurichten und ein Kloster aufzubauen. ${ }^{9}$

\section{Darstellung Der Dokumente}

Ich nenne $[\mathrm{L}]$ die Urkunde des ursprünglichen Vertrag von Lonyz, die verloren ist und durch eine päpstliche Bestätigung $[\mathrm{P}]$ vom I 8 . April 1223 bekannt, und [A] (I238/1 240) und [B] (I264) die zwei späteren Überlieferungen. So gibt es drei verschiedenen Überlieferungsversionen. ${ }^{\circ}$

$[\mathrm{P}]^{11}$ ist kein eigentliches Vidimus, sondern die Bestätigung des Vertragstextes durch den Papst, dessen Echtheit durch die Anwesenheit der Siegel bestätigt wird:

7 Ebd., 26-27 Nr. 40.

8 Ebd., i 8-i 9 Nr. 26.

9 Preterea autem in castro Colmensi curiam propriam et conventum, qualem voluerit, ipse episcopus Prutie habebit, vgl. Ebd., 30 Nr. 4I).

10 Es gibt auch zwei Kopien von [B] ([C] und [D]), die sich nur in geringfügigen Abweichungen in der Schreibweise unterscheiden. [C], deren Datum unbekannt ist, ist verschwunden. Kazimierz Stronczyński gab ein ähnliches Faksimile, vgl. Kazimierz Stronczyński, Wzory pism dawnych w przerysach wystawione, i objaśnione drukowanem i wyczytaniem, Tl. I, Obejmująca pismo dyplomatów od roku I 228 do I 536 (Warszawa: Kommissyi Rządowej Sprawiedliwości, I 839), I 3-I 4 Nr. I 3 . Diese Abschrift hatte i 839 noch vier Siegel darauf. [D] stammt aus dem frühen I 5. Jh. Sie war im Marienburg-Archiv (benannt: „Privilegia des Colmischen Landes“, Fol III) aufbewahrt, dann verschwunden (herausgegeben von Friedrich von Dreger: Codex diplomaticus. Oder Uhrkunden, So die Pommersch-Rügianisch-und Caminische, auch andere benachbarte Lande angehen. Aus lauter Originalien oder doch archivischen Abschrifften in chronologischer Ordnung zusammen getragen, und mit einigen Anmerckungen erläutert, v. Friedrich von Dreger, t. I, bis I 269 incl. (Stettin: Johann Friderich Spiegel, I 748), I 0 5- 07 Nr. 58). Diese zwei Kopien werden bei der Untersuchung vernachlässigt.

${ }_{11}$ Archivio Segreto Vaticano, Reg. Vaticani Hon. III, t. IV, ep. 138, fol. $38 \mathrm{r}$ (vgl. CD-ROM Reg. Vat. I 2, pont. an. VII-VIII I 222-I 224) (Ausgabe: Preußisches Urkundenbuch, I. I, 33-34 Nr. 44; Vetera monumenta Poloniae et Lithuaniae gentiumque finitimarum historiam illustrantia: maximam partem nondum edita ex tabularis Vaticanis deprompta collecta ac serie chronologica disposita, Bd. I, Ab Honorio PP. III. usque ad Gregorium PP. XII. I217-I409, hrsg. v. Augustin Theiner (Romae: Typis Vaticanis, I 860, I 8- i 9 Nr 39 (Augustin Theiner gibt den gleichen Text wie Rudolf Philippi - außer zwei Namen, die zu „Muthe“ und „Charuse“ geändert wurden)]. Es 
Ex litteris sane tam nobilis viri C., Mazovie et Cuiavie ducis, ac venerabilis fratris nostri G. episcopi et dilectorum filiorum capituli Plocensis, quam aliorum plurium episcoporum et nobilium sigillis munitis accepimus [...]. ${ }^{12}$

Der Papst bescheinigt, dass der Bischof und das Kapitel von Płock Christian die Zehnten, die geistlichen Rechte und den Besitz geschenkt haben, die sie im Kulmerland besaßen. ${ }^{13}$ Er zeigt an, dass Konrad dieses Gebiet gegeben hat (terram eandem, ab omni exactione libera) mit vier villas (Colno, Mirche, Charnese und Bolemino), drei castra (Gruzenz, Wabsk, Copriven) und drei possessiones (Villisaz, Kisin und Ploth), insgesamt zehn spezifische Standorte. ${ }^{14}$ Der einzige geäußerte Grund für die Schenkung ist die Frömmigkeit (intuitu pietatis) ohne irgendeine Bezugnahme auf den militärischen Kontext oder Christians Hilfe.

[A] ist ein Vidimus von I $238-\mathrm{I} 240 .{ }^{15}$ Auf dem Manuskript liegen die Reste von 5 Laschen von Zeugensiegeln. Ob die Siegel tatsächlich angebracht wurden,

gab zwei Transkriptionen dieser päpstlichen Bestätigung, beide von I 264 nach Max Perlbach, Preussisch-polnische Studien zur Geschichte des Mittelalters, Bd. I, Zur Kritik der ältesten preussischen Urkunden (Halle: Max Niemeyer, I 886), 26. Eine wurde I 264 von Anselm, Bischof von Ermland, für den Deutschen Orden durchgeführt und im Diözesanarchiv von Kulm aufbewahrt (Ausgabe: Codex Diplomaticus Regni Poloniae et Magni Ducatus Lithuaniae, t. IV, In quo totius Prussiae Res continentur, hrsg. v. Maciej Dogiel (Vilnae: Typograhia Regia \& Reipub[lice] CC. RR. Scholarum Piarum / Regimonti-Lipsiae: Officina Libraria Johannis Jacobi Kanteri, 1764), 2-3 Nr. III. Die zweite ist nach Perlbachs Angaben in „Transumpte der Cistercienser Äbte", S. I 53 veröffentlicht.

I2 Preußisches Urkundenbuch, I.I, hrsg. v. Philippi, 33 Nr. 44. Dann, im Bestätigungsformular: terram, castra et alia supradicta, sicut ea omnia iuste, canonice ac pacifice possides, et in predictis litteris plenius continetur [...]. Im Gegenteil bemerkt man, dass die päpstliche Bestätigung der Schenkung von Cecoviz durch Władysław von Kalisz (29. Mai I 2 I 8) wie ein Vidimus sorgfältig geschrieben wurde: de verbo ad verbum, vgl. Preußisches Urkundenbuch, I.I, hrsg. v. Philippi, I 9-20 Nr. 28.

I3 [...] cedentibus tibi predictis episcopo et capitulo decimas et omnia iura spiritualia cum possessionibus, que in terra Colmensi, ut dicitur, obtinebant [...], vgl. ebd., 33 Nr. 44.

14 Meint terra Colmensi das ganze Kulmerland, oder nur das Gebiet unter dem castrum von Kulm?

is Vgl. die Angaben von Walther Hubatsch: Regesta historico-diplomatica Ordinis S. Mariae Theutonicorum I198-I525, Pars II, Regesta Privilegiorum Ordinis S. Mariae Theutonicorum / Regesten der Pergament-Urkunden aus der Zeit des Deutschen Ordens, bearb. unter Mitwirkung zahlreicher anderer v. Erich Joachim, hrsg. v. Walther Hubatsch (Göttingen: Vandenhoek \& Ruprecht, 1948), 5 Nr I 8 (Berlin, Geheimes Staatsarchiv Preußischer Kulturbesitz, XX. Hauptabteilung, Pergamenturkunden, Schiebl. Culmer Diözesan Archiv, Nr. I (Ausgabe: Preußisches Urkundenbuch, I.I, hrsg. v. Philippi, 27-3 I Nr. 4 I [A.]). Die Urkunde ist nicht datiert: Max Perlbach kalkuliert, es würde zwischen August I 238 und Februar I 240 erfasst, vgl. Perlbach, Preussischpolnische Studien, 28-30. Christian wurde I 233 gefangen und im Frühjahr I 238 entlassen (sein Name erscheint in einer Urkunde vom I I. Juni I 238, vgl. Preußisches Urkundenbuch, I. I, hrsg. v. Philippi, 97-98 Nr. I 29. Entsprechend wurde die Urkunde später verfaßt. Im April I 240 verließ Christian Preußen. Er beschwerte sich beim Papst über die Haltung der Ritterbrüder 
ist nicht sicher, da die Einschnitte nur zur Hälfte gemacht wurden. Dieses Vidimus enthält keines der üblichen Einführungselemente. Danach auf dem Pergament folgt, nach einer Leerstelle, die Kopie - ohne jegliche Spuren von einem Vidimus oder Datum - der Urkunde, durch welche Christian von Preußen in den Besitz des Dorfes Rehden (Radzyń) kam. ${ }^{16}$ Handelt es sich um eine unfertige und nie verwendete Version? Der Herzog schenkt einen „Teil des Landes von Kulm“ (partem territorii Colmensis) mit einer Liste von castra, villae et possessiones und deren Nebengebäude und -gebiete, mit allen herzoglichen Rechten. [A] erwähnt nämlich 23 quondam castra und 28 Dörfer, d. h. 5 I spezifische Orte. Außerhalb von Kulm befinden sich die zehn in [P] genannten Orte: drei bereits als castra (Gruzenz, Wabsko, Copriven) gemeldet, vier, die zuvor als Dörfer oder possessiones und nun in die Liste der castra (Kysin, Ploth, Velsaz und Colno) enthalten, und drei Dörfer (Mirche, Charnese und Bolemino). ${ }^{17}$ Die Schenkung beinhält centum villas ac possessiones ac hereditates in eodem dominio Colmensi. 28 werden erwähnt; die ersten sechs stehen unter der Kontrolle von Konrad, und die 22 anderen werden dem Wojewoden Żyro weggenommen. Darüber stehen hereditates des Herzogs in der Gegend von Loza (später Kulmsee (Chełmża)), villae im Gruth-Wald (dt. Frankenhagen, poln. Gruta, $8 \mathrm{~km}$ südöstlich von Rehden) mit dem Wald selbst und dazu ein anderes Gebiet. Seltsamerweise bleibt dieses letztere anonym, aber die Historiker sind sich heute darüber einig, dass es sich um das Löbauer Land handelt, das zwischen dem Herzog und den Heiden umstritten war. Konrad motiviert seine Schenkung auf der Hilfe von Christian, der cum eius bona voluntate den polnischen Kreuzritterfürsten genehmigte, das von den Heiden zerstörte castrum Kulm wiederaufzubauen - ein Beweis, dass dieses castrum vor dem Vertrag unter der Autorität des Bischofs stand. Danach verzichtete Christian auf die Burg, wie

in einem Brief, der um Februar I 240 adressiert und durch die Antwort von Gregor IX. am I I. April I 240 bekannt wurde, vgl. Preußisches Urkundenbuch, I.I, hrsg. v. Philippi, I00- Io2 Nr. I 34. Vermutlich wohnte Christian im Zisterzienserkloster Grünhain oder in deren Nähe (vgl. Perlbach, Preussische-polnische Studien, 29). Gregor IX erwähnt die Gebiete, die Christian dem Deutschen Orden gegeben hat und die er durch Schenkung oder Kauf erworben hatte ([...] terram quam idem partim elemosinis principum catholicorum ac aliorum fidelium pretio comparavit, partim ex done nobilis viri ducis Conradi [...], vgl. Preußisches Urkundenbuch, I. I, hrsg. v. Philippi, I o I Nr. I 34). So hatte unbedingt der Papst die betreffende Urkunde vor seinen Augen. Also wurde sie am spätesten bei Februar I 240 kopiert. Das vidimus von I238-I 240 wurde daher zwischen Frühling von I 238 und Februar I 240 abgeschrieben.

16 Preußisches Urkundenbuch, I. I, hrsg. v. Philippi, 36-37 Nr. 50.

17 Die Reihenfolge, in der die Schenkungen getätigt werden (castra dann villas) ist verschieden von diesen in $[\mathrm{P}]$ (villae, castra, possessiones), aber das scheint nicht signifikant zu sein - abgesehen davon, dass die Reihenfolge von $[\mathrm{A}]$ und [B] hypothetisch eine wichtige Rolle der Befestigungen hindeuten könnte. 
P. Grochowski es meint ${ }^{18}$ Der Text stipuliert dann, dass der Bischof von Płock sein Eigentum und seine Rechte gewährt hat, in predicto Colmensi dominio, einschließlich Carnovo und Papavo. Konrad erlaubt Christian, im castrum einen Hof (propria curia) und ein conventum zu errichten. Eine letzte Bestimmung besagt, dass in allen Angelegenheiten, die die Herrschaft über das Land Kulm betreffen (ad dominium Colmensis territorii) - ausgenommen das Vermögen, das der Bischof durch die Schenkungen der Gläubigen oder durch Kaufen erhalte könnte jeder, der dieses Land besitze, die entsprechenden Einnahmen halb und halb mit dem Bischof teilen müsse. Das beweist ${ }_{2}$ dass Konrad Christian nicht das ganze Kulmerland geschenkt hat. Schließlich ist Henryk, Herzog von Schlesien, diesen Bestimmungen ausgenommen und soll Christian direkt zustimmen. ${ }^{19}$ Die Grenzen des Kulmerlandes sind genau angegeben, identisch mit anderen Dokumenten: Weichsel, Ossa, Drewenz und die Grenzen (terminos) von Prußen.

Es gab noch ein zweites, verlorenes Zisterzienser-Vidimus, dessen Inhalt in einem anderen Vidimus ([E]) von Georg von Delau, dem Offizial von Ermland, am 7. Oktober I 5 I 4 , erhalten ist. ${ }^{20}$ Üblicherweise steht die Einführung dieses $V i$ dimus vor den Abschriften vieler Akten; die Abschrift des Lonyzer Vertrags ist die

18 Grochowski, Chrystian, ıоo.

19 Benedykt Zientara, "Sprawy pruskie w polityce Henryka Brodatego," Zapiski Historyczne 4I, H. 4 ( 1976): 27-42; ders., Henryk Brodaty i jego czasy (Warszawa: Trio, I 975 (I. Ausgabe); I 997 (2. Ausgabe)). Henryk Brodaty von Schlesien war sehr aktiv im Kampf gegen die Heiden. Im Jahr 1222 restaurierte er das castrum Kulm und setzte er darin ein castellanus ein (vgl. Schlesisches Urkundenbuch, hrsg. v. der Historischen Kommission für Schlesien, bearb. v. Heinrich Appelt, Bd. I, 2. Lieferung, I2I7-I230 (Wien-Köln-Graz: Verlag Hermann Böhlaus Nachf., I 968), I 66-I67, Nr. 227). Er nahm im Juli I 223 an dem Heerzug gegen die Prußen teil. Aber I 224 niedermetzteln die Pruteni die Grenzbesatzungen. Möglicherweise ratete dann Henryk, die Deutschordensbrüder in das Kulmerland einzuführen. Es ist ganz möglich, wie Pawel Grochowski es vermutet, dass eine Art von „Kondominium“ Christians und des Herzogs von Schlesien entstand (vgl. Grochowski, Chrystian, roo).

20 Urkundenbuch des Bisthums Culm, Theil II, Das Bisthum Culm unter Polen 1466-I774, hrsg. v. Carl P. Woelky, Neues Preussisches Urkundenbuch. Westpreussischer Theil, II. Abtheilung, Urkunden der Bisthümer, Kirchen und Klöster I (Danzig: Commissionsverlag von Theodor Bertling, I 887), 663 Nr. 803; C. P. Woelky erwähnt Delau’s Einführung und dann den Hinweis auf R. Philippis Ausgabe von [A]: In nomine sancte et individue Trinitatis patris et filii et spiritus sancti. Amen. Noverint universi hoc presens transsumptum inspecturi, quod nos Georgius de Delau, cantor et canonicus Warmiensis, necnon reverendi in Christo patris ac domini, domini Fabiani, dei et apostolice sedis gratia episcopi eiusdem Warmiensis ecclesie, vicarius et officialis generalis in spiritualibus, habuimus, $v$ id im us et diligenter inspeximus quasdam litteras donationis, empcionis, confirmationis, inscripcionis, consensus, obligacionis ac dotationis ecclesie Culmensis quorundam inclitorum principum, regum, ducum, baronum, militum etc. suorum que sigillorum appensione munitas, omnimoda suspicione carentes. In primis videlicet serenissimi principis Conradis, ducis Masovie Cuyavie cuius tenor in continentia erat ista. 
erste. Der authentifizierte Text kann nicht $[\mathrm{A}]$ sein, weil er als mit 9 Siegeln versehen beschrieben wird, von denen die letzten beiden identifizierbar waren: das des Abtes von Grünhain und das eines Propsts namens Konrad mit dem Bild des heiligen Stephanus (T. Jasiński identifizierte es mit dem des Klosters St. Stephanus von Zeitz im Bistum Naumburg ${ }^{21}$ ). Es gab also zwei Vidimus, die von den Grünhainer Zisterziensern aus der ihnen vorgelegten Version von [L] durchgeführt wurden. Ihre Übereinstimmung deutet darauf hin, dass sie gleichzeitig transumiert wurden. ${ }^{22} \mathrm{Da}[\mathrm{E}]$ keine neuen Elemente anbringt, wurde es aus dieser Diskussion ausgeschlossen.

[B] ist ein Vidimus des päpstlichen Legaten Anselm Bischof von Ermland, auf Antrag der Würdenträger des Ordens im I 264 ausgefertigt, auf dem der Legat und die Gebietiger ihre Namen eintrugen und an dem sie ihre Siegel brachten. ${ }^{23}$ Der Text ist $[\mathrm{A}]$ gleich, mit vier Ausnahmen, was die Neugier aller Forscher weckte:

21 Tomasz Jasiński, "Die Verleihung des Kulmerlandes an den Deutschen Orden im Jahre I 228 im Licht des Vertrags von Lonyz (1 222)," in Tomasz Jasiński, Kruschwitz, Rimini und die Grundlagen des preussischen Ordenslandes. Urkundenstudien zur Frühzeit des Deutschen Ordens im Ostseeraum, Quellen und Studien zur Geschichte des Deutschen Ordens 63, Veröffentlichungen der Internationalen Historischen Kommission zur Erforschung des Deutschen Ordens 8 (Marburg: N. G. Elwert Verlag, 2008), I -20, hier 9 (die deutsche Version des in Anm. 3 zitierten Aufsatzes, die doch im Bezug auf dortige Anmerkungen nicht ganz mit dem polnischen Original stimmt). Von den anderen sieben Siegeln waren drei bischöfliche Siegel (Nr. 2, 3 und 5); zwei waren Siegel von Domkapiteln (Nr. 4 und 7); und die anderen (Nr. I und 6) sind nicht identifizierbar. Max Perlbach weist die bischöflichen Siegel zu drei sächsischen Bischofen (vgl. Perlbach, Preussisch-polnische Studien, 29: „vermutlich die von Meissen, Merseburg und Naumburg").

22 Perlbach, Preussisch-polnische Studien, 28: „Doch sind sicherlich die beiden Exemplare gleichzeitig geschrieben“"

23 Berlin, Geheimes Staatsarchiv Preußischer Kulturbesitz, XX. Hauptabteilung, Pergamenturkunden, Schiebl. ı 9, Nr. 25 (Ausgabe: Preußisches Urkundenbuch, I. I, hrsg. v. Philippi, 27-3 I Nr. 4I [B.]). Das waren die Siegel von Anno von Sangershausen (Hochmeister), von Konrad von Nürnberg (Deutschmeister), von Ludwig von Baldersheim (Landmeister von Preußen), und vom Komtur von Böhmen; aber nur bleiben die Faden. Am I. Februar I 264 traten der Bischof und das Domkapitel von Kulm in den Deutschen Orden ein und bei dieser Gelegenheit erneuerte der Bischof Friedrich die Schenkungen des Domkapitels (vgl. Urkundenbuch des Bisthums Culm, Theil I, Das Bisthum Culm unter dem Deutschen Orden I243-I466, hrsg. v. Carl P. Woelky, Neues Preussisches Urkundenbuch. Westpreussischer Theil, II. Abtheilung, Urkunden der Bisthümer, Kirchen und Klöster I (Danzig: Commissionsverlag von Theodor Bertling, I 885), 49-50 Nr. 72) und bestätigte mehrere Dokumente über seine Kirche, wahrscheinlich um den Anfechtungen der Płocker Kirche zu entgegnen, vgl. Perlbach, Preussisch-polnische Studien, 27). Der Vertrag von 1222 wurde in zwei Exemplare kopiert, eines wurde davon im Diözesanarchiv von Kulm bewahrt, und das andere wurde dem Orden übergeben. I 466 archivierte Polen in Warschau die Kopie, die der Orden aufbewahrt hatte. Max Perlbach verglich die beiden und schloss daraus, dass sie den selben Text abgeschrieben hatten. 
- [B] gibt 43 spezifische Namen: die der ersten I I castra, die in [A] vorhanden sind. Es lässt aber die folgenden I 2 weg - mit Ausnahme von zwei, die in der Liste der Dörfer enthalten sind.

- [B] erwähnt die Schenkung von 32 Dörfern, darunter die 28 von [A] angegebenen, dazu noch zwei der castra von $[\mathrm{A}]$ mit einem anderen Status (Postolko/ /Postolsco ${ }^{24}$ und Ostrowich/Ostrovith) und schließlich zwei weitere Dörfer, die in [A] nicht erscheinen (Pomzino und Clezchowar).

- Es sagt nichts über das Land, das zwischen Konrad und den Heiden umstritten ist.

- Schließlich lässt er den Hinweis auf „Preußen“ weg, obwohl [A] von „dem Bischof von Preußen“ "sprach (exceptis bonis predictis, que supradictus episcopus Prutie ibi habet [...]). Christian war jedoch von I 2 I 5 bis I 243 Bischof von Preußen; zu dieser Zeit ordnete Innozenz IV. die Aufteilung Preußens in vier Bistümer (darunter eine für Kulmerland) an, und die Erwähnung eines episcopus Prussie verschwand.

Fassen wir die Fakten zusammen. Es gibt drei verschiedene mit dem Vertrag von Lonyz verbundenen Überlieferungen: eine sehr kurze und zwei viel längere. Der Inhalt der kürzesten wird in den beiden anderen vollständig wiedergegeben. Diese sind weitgehend identisch, außer in vier spezifischen Punkten: drei nur in der ältesten $[A]$, und einer nur im neueren $[B]$.

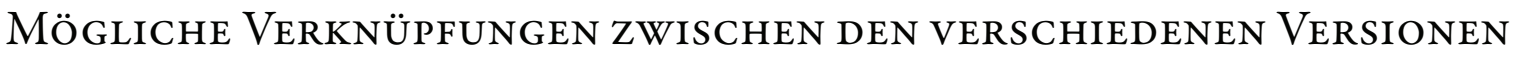

Ich werde hier die logischen Möglichkeiten untersuchen, die den notwendigen Rahmen für die Untersuchung bieten. Aber während die Logik es ermöglicht, die Beziehungen zwischen den Fakten herzustellen, begründet sie nicht ihre Existenz oder Wahrheit. Ich lehne die sehr unwahrscheinliche Hypothese ab, dass in $[\mathrm{P}]$ die Überlieferung [L] abgekürzt wurde: wenn der ganze Inhalt nicht gegeben wäre, wäre seine Bestätigung für den Bischof irrelevant. Daher wird es davon ausgegan-

24 Eindeutig beziehen sich diese zwei Namen auf den gleichen Ort, vgl. Stownik historycznogeograficzny ziemi chetmińskiej w średniowieczu, bearb. v. Krystyna Porębska, u. Mitarbeit v. Maksymiliana Grzegorza, red. v. Marian Biskup, Słownik historyczno-geograficzny ziem polskich w średniowieczu I (Wrocław-Warszawa-Kraków-Gdańsk: Zakład Narodowy im. Ossolińskich, I97I), Iо I (elektronische Edition: http://www.slownik.ihpan.edu.pl/browse. php?d=2 (Chełmno), red. v. Tomasz Jurek, zugegriffen am 5. Juli 20 19): „osada nie zidentyfikowana lub zag., zapewne na $\mathrm{N}$ od Torunia [...]“; „Nie da się wyłączyć ewentualności, że Postolko i Postolsko to jedna i ta sama osada“. 
gen, dass $[\mathrm{P}]$ eine getreue Inhaltsversion der Vertragsüberlieferung $[\mathrm{L}]$ liefert. So kann man zwei Hypothesen stellen:

- Hypothese I: $[A]$ und [B] schrieben eine interpolierte und erweiterte Version der verlorenen Vertragsurkunde ab.

Diese Version ist unbedingt später als $\mathrm{I} 223$ und muss vor oder gleich I 228/ I 230 entstanden sein, denn, wie Tomasz Jasiński deutlich betonte, gab Herzog Konrad die Kulmer Landgüterkastellanei (poln. kasztelania majątkowa) dem Deutschen Orden im April I 228, während Christian den Deutschordensbrüdern alle seine dort liegenden Besitzungen I 23 I abtrat. In diesem Fall, da [A] und [B] vom gleichen Text stammen würden, wird ein großer Teil des Inhalts durch ihre gemeinsame Schnittmenge gegeben. Zwei Hypothesen sind dann möglich - und zwarnicht exklusiv:

- Hyp othese i a : [A] hat Ergänzungen gemacht, so dass [B] näher an der ursprünglichen Verleihung wäre;

- Hyp othese i b: [B] hat Elemente entfernt oder modifiziert;[A] wäre daher nahe an der ursprünglichen Verleihung;

- Hypothese 2: [A] und [B] haben selbst die Vertragsüberlieferung von I $222[\mathrm{~L}]$ ergänzt und geändert.

In diesem letzten Fall bedeutet dies, da die beiden Kopien fast identisch sind, dass $[\mathrm{B}]$ aus dem früheren $[\mathrm{A}]$ stammt, was möglich wäre, weil beide Dokumente vorbereitet und in der Kanzlei der Bischöfe von Kulm aufbewahrt wurden ${ }^{25}$. [A] scheint das Diözesanarchiv nie verlassen zu haben; ebenso wurde eine der beiden Abschriften von [B] im selben Archiv aufbewahrt. Es ist fast sicher, dass der Deutsche Orden kein Exemplar hatte: erst I 264 wurde er auf die Verleihung aufmerksam. Andernfalls hätten die Gebietiger ihre Namen und Siegel nicht am Ende der Urkunde angebracht, wie es T. Jasiński bemerkt hat. ${ }^{26}$ Zudem achtete Legat Anselm, der die Fassung 1264 beglaubigte, darauf, dass die Würdenträger des Ordens die Urkunde gesehen hatten und transumieren ließen:

In huius rei testimonium presens scriptum nostri ac honorabilium virorum fratris Annonis hospitalis sancte Marie Theutonicorum Jherosolimitani magistri, fratris Conradi de Nuremberg preceptoris Allemanie et fratris Lodewici de ... magistri Pruscie et com-

25 Gewiss wurde [B] in Thorn, nicht in Kulmsee, ausgestellt, aber das Vidimus war ein Antrag des Ordens, der in Thorn einen Konvent hatte. Dazu ist eine Aufenthalt Anselms in Thorn ganz möglich.

26 Jasiński, “Die Verleihung," I I. 
mendatoris Boemie qui etiam suprascriptas litteras viderunt et perlegi fecerunt sigillorum munimine roboramus. ${ }^{27}$

Allerdings ist zu beobachten, dass Anselm die Fassung [B] und nicht [A] authentifiziert hat: entweder hat ihm der Bischof Friedrich nur diese vorgelegt, oder [A] wurde einvernehmlich abgelehnt, weil dessen Inhalt den Orden störte. Darüber achtete Anselm am Beginn des (sehr kurzen) Vidimus darauf, dass er kein anderes Vidimus authentifiziert habe, sondern die litterae mit ihren Siegeln:

Anselmus dei gratia episcopus Warmiensis Apostolice sedis legatus. Universis ad quos presens scriptum pervenerit salutem in domino sempiternam. Litteras subnotatas veris sigillis subscriptorum munitas vidimus et perlegimus in hec verba. ${ }^{28}$

Die Hypothese, dass [B] auf [A] basiert, scheint ausgeschlossen zu sein. Es bleibt also nur die Hypothese I mit ihren zwei Optionen. Daher muss man die Existenz einer Urkunde anerkennen, die unter den Urkunden des kulmischen Bischofs vorhanden war und zweimal, um I 240 und I 264, vidimiert wurde. Diese Urkunde werde ich [L'] nennen.

\section{Die Fragen}

Warum gab es eine kurze Fassung um I222/ I223 und zwei viel längere Fassungen 20 und 40 Jahre später? In $[\mathrm{A}]$ und $[\mathrm{B}]$ ist eine Urkunde abgeschrieben, die nicht das Original von 1222 ([L]) war. Woher kam diese Urkunde und warum enthielt sie eine viel längere Liste von Schenkungen? Dazu warum gibt es diese Unterschiede zwischen den zwei längeren Fassungen? Handelt es sich um legitime Hinzufügungen/Zurücknahmen, also um eine Aktualisierung mit Berücksichtigung auf der späteren Entwicklung des Kulmerlands, oder um eine politisch motivierte Fälschung? Ist das entscheidbar? Darüber diskutieren deutsche und polnische Historiker seit I 50 Jahren: Sind $[\mathrm{A}]$ und [B] beide Fälschungen, oder nur eine davon? Wie in vielen anderen Fällen der Geschichte der Anfänge der Eroberung des Preußenlands sind wir in einem Teufelskreis geraten:

- die Echtheit und die Abstammung von Handschriften helfen dazu, die Realität und die Abfolge der Fakten zu ermitteln;

27 Berlin, Geheimes Staatsarchiv Preußischer Kulturbesitz, XX. Haupabteilung, Pergamenturkunden, Schiebl. I09, Nr. 25.

28 Ebd. 
- umgekehrt hilft die Reihenfolge der Fakten, die Echtheit und die Abstammung der Handschriften zu erklären.

Wie es T. Jasiński bemerkt hat, gehört dieser Vertrag „zu den schwierigsten Rätseln der polnischen und deutschen Diplomatik“. ${ }^{29}$ Um dieses Rätsel zu beantworten, haben Historiker viele Szenarien vorgeschlagen, die mehr oder weniger kompliziert sind. Ich werde kurz Max Perlbachs Szenario vorstellen und das von T. Jasiński entwickeln..$^{\circ}$

Laut M. Perlbach gibt [B] eine getreue Fassung der Vertragsurkunde und [A] ist eine "Fälschung" vom Bischof Christian. Er kommt zum Schluss, dass [A] die erste Urkunde interpoliert hat, um es Christian zu ermöglichen, das gesamte I 230/I 23 I $^{31}$ übertragene Eigentum von den Deutschordensbrüdern zurückzugewinnen. In diesem Fall wäre $[B]$, obwohl jünger, näher an der authentischen Version der Vertragsurkunde. Dieses Szenario ist konsistent, aber man muss noch festlegen, welches Dokument die Autoren von [B] kopiert hatten, da ihre Version länger als die päpstliche Bestätigung ist. Außerdem, wie kann man den starken Anstieg der Schenkungen zwischen I 223 und I 264 erklären? Obwohl präzise und

29 Jasiński, "Die Verleihung," I.

30 Tomasz Jasiński hat die ganze Reihe der Thesen vorgeschlagen, vgl. Jasiński, "Die Verleihung," 2-3); vgl. besonders: Preußisches Urkundenbuch, I.I, hrsg. v. Philippi, 3 I-32, Anm. 2 auf der S. 3 I; Wojciech Kętrzyński, O ludności polskiej w Prusiech niegdyśs krzyżackich (Lwów: Zakład Narodowy im. Ossolińskich, I 882), 47-49; Perlbach Preussisch-polnische Studien, 26-38; Alfred Lentz, "Die Beziehungen des Deutschen Ordens zu dem Bischof Christian von Preussen. Ein Beitrag zur Geschichte der Gründung des Deutschen Ordensstaates," Altpreussische Monatsschrift 29 ( I 892): 369 ; Stanisław Zakrzewski, "Nadania na rzecz Chrystiana, biskupa pruskiego w latach I 2 17-I 224," Rozprawy Akademii Umiejętności. Wydziat hist.-filoz., ser. II, I 7 ( 1902 ): 237-332, besonders 238-267; Józef Paradowski, Osadnictwo w ziemi chetmińskiej w wiekach średnich (Lwów: Kasa im. J. Mianowskiego, 1936), 29-51; Janusz Bieniak, "Studia nad dziejami ziemi chełmińskiej w okresie piastowkim,” Rocznik Grudziądzki 5-6 (1970): 5-69, hier i 8-ı 9; Jan Powierski, "Studia nad strukturą administracyjno-terytorialną ziemi chełmińskiej i michałowskiej w okresie piastowskim," Bydgoskie Towarzystwo Naukowe. Prace wydziału nauk bumanistycznych, ser. C, 13 (1973): 3-86.

31 Perlbach, Preussische-polnische Studien, 38: „Nur die kürzere Fassung des Lonyzer Vertrags ist somit als ursprünglicher Text desselben anzusehen und für die Interpretation dieser Urkunde zu verwenden, der längere Text ist eine um I 240 entstandene Fälschung des Bischofs“. W. Kętrzyński hatte um I 235 eine Fälschung des Ordens angeprangert, mit dem Ziel, sich zu Lasten des Bischofs so viel Eigentum wie möglich im Kulmerland zu verschaffen. Die Länge des ersten Satzes erschien ihm verdächtig, ebenso wie eine Reihe lateinischer Fehler obwohl zwei Kanzler unter den Zeugen standen, vgl. Wojciech Kętrzyński, Der Deutsche Orden und Konrad von Masovien I225-I235 (Lemberg: Subrynowicz und Schmidt, I 904), I 7 I- I 75 . Aber dieses Szenario ist nicht überzeugend, denn der Orden erhielt I 230 das gesamte Kulmerland von Konrad, ohne irgendeine Einschränkung. Die Liste von I 222 ist zwar umfangreich, aber auch restriktiv. Schließlich sind die 'Kuriositäten' der Sprache nicht unbedingt ein Hinweis einer Fälschung. 
nützlich, vernachlässigt Perlbachs Studie die päpstliche Bestätigung von I 223. Die Frage der Existenz einer kurzen Fassung und einer langen Fassung der Vertragsurkunde wird nicht von ihm untersucht: er hatte seine Überlegungen auf die Unterschiede zwischen [A] und [B] konzentriert. Allerdings ist eine Analyse des Problems der Existenz von zwei Versionen unterschiedlicher Größen notwendig, um ein überzeugendes Szenario zu entwickeln.

I 992 schlug T. Jasiński eine neue Erklärung vor. Dies ist die umfassendste Arbeit zu diesem Thema, die ein originales und oft überzeugendes Szenario vorschlägt. Um I 222, in Lonyz (wahrscheinlich Łońsk in Kujawien), hätte Konrad das Kulmerland als sog. Landgüterkastellanei (poln. kasztelania majątkowa) an Christian gegeben (d. h. ein castrum und nur einige ihm zugewiesene Siedlungen der älteren herzoglichen Kastellanei). Dieser Punkt scheint nämlich entscheidend für das Verständnis der ersten Schenkung zu sein. ${ }^{32}$ I 227 hält der Bischof noch die Gegend, wie die Bestätigung von Gregor IX. es zeigt, die die von Honorius III. wiederholt. Anfang März I 228, wahrscheinlich als sie sich in Skaryszew ${ }^{33}$ trafen, übergab Christian das Kulmerland (und exakter: die Kulmer Landgüterkastellanei) an Konrad zur Übertragung dem Deutschen Orden (s. den Vertrag von Biecz, 23. April I 22834):

„Weil das Kulmerland noch am 11. 6. 1227 in Händen Christians war und Konrad es bereits am 23. 4. 1228 dem Deutschen Orden verlieh, ist davon auszugehen, dass Konrad das Kulmerland innerhalb dieses Zeitraums zurückerhalten muss“.35

Aber das konnte nur gegen eine Entschädigung durchgeführt werden. Konrad schenkte dann sein eigenes Eigentum und das des Wojewoden Żyro, das kurz zuvor wegen seiner Beteiligung am Świętopełk-Angriff auf Leszek Biały eingezogen worden war. ${ }^{36}$ Diese Besitztümer wurden innerhalb der Verwaltungseinheit der „Hundertschaften“ zusammengefasst, was die Schenkung von centum villas er-

32 Jasiński, “Die Verleihung,” I 2: „Aus ihr geht hervor, dass Bischof Christian das Kulmerland in Form der wirtschaftlichen Kastellanei mit vier herzoglichen Dörfern, drei Besitzungen, drei Burgen und mit allen Besitzungen des Plocker Bistums erhalten hat. Diese Interpretation der päpstlichen Dokumente vom I 8.4.I 223, die auch die Übertragung der Kastellangewalt und Bischof Christian impliziert, findet ihre Bestätigung darin, dass im nächsten Jahr der Kulmer Kastellan in der Umgebung Bischof Christians erscheint“.

33 Codex diplomaticus et commerationum Masoviae generalis / Zbiór ogólny przywilejów i spominków mazowieckich, Bd. I, hrsg. v. Jan K. Kochanowski (Warszawa: Wł. Łazarskiego, I 9 19), 272-273 Nr 254.

34 Preußisches Urkundenbuch, I. I, hrsg. v. Philippi, 47 Nr. 64.

35 Jasiński, "Die Verleihung," i 5.

36 Ebd., 17. 
klärt. Damit sicherte Konrad zugleich Christian seine Zukunft im Kulmerland und übertrug dem Deutschen Orden das Gebiet. Um I 240, ohne die authentischen Urkunden von I 222 (an Konrad zurückgegeben) und I 228 (verloren, als die Heiden seine Residenz in Zantir (Zantyr) zerstörten), verfasste Christian zwei Falsifikate, um sich der Herrschaft des Deutschen Ordens zu widersetzen. ${ }^{37}$ Konrad hätte zugestimmt, sein Siegel auf [B] anzubringen, weil er um I 240 mit dem Orden über das Land Löbau stritt; Christian konnte jedoch nicht die herzogliche Zustimmung für $[\mathrm{A}]$ erhalten, der ihm dieses Land pro bono pacis gewährte. T. Jasińskis Schlussfolgerungen über die Fassungen [A] und [B] sind wie folgt:

$-\mathrm{I}^{\circ}$ Sie müssen einem einzigen Autor zugeordnet werden (er stellt fest, dass „die zwei gleichlautenden Falsifikate [...] von derselben Person formuliert worden sein müssen ${ }^{{ }^{3} 8}$ ). [A] (I 240) kommt von [B] ( 1264$)$. [A] hat den Inhalt von [B] absichtlich erweitert:

„Aus diesem Vergleich geht hervor, dass wir in B nicht mit einer mechanischen Auslassung zu tun haben; vielmehr ist die Schenkung in Version A absichtlich gegenüber B erweitert worden“. ${ }^{39}$

Und so schließt er: „So ist also nicht etwa Text B aus A, sondern umgekehrt Text $A$ aus $B$ entstanden “.. ${ }^{40} \mathrm{Da}[\mathrm{B}]$ von $\mathrm{I} 264$ und $[\mathrm{A}]$ von $\mathrm{I} 240$ stammt, will natürlich T. Jasiński darauf hinweisen, dass $[\mathrm{A}]$ vom Text ausgeht, den $[\mathrm{B}]$ vidimierte.

$-2^{\circ}[\mathrm{B}]$ kann nicht die ursprüngliche Fassung des Vertrags von I 222 sein: „Viele Umstände sprechen dagegen“. Es gibt zu viele Fehler in der Diplomatik, als ob zwei verschiedene Dokumente „miteinander verbunden“ worden wären. Gedko von Płock sollte in der ersten Person sprechen; doch seine Schenkung wird nicht von ihm selbst, sondern vom Herzog Konrad mitgeteilt. Es gibt auch Anachronismen wie die Verwendung des Adverbs olim in Gedkos Schenkung, die für I 222 nicht erklärt werden kann (de omnibus villis et possessionibus, et de domni iure, tam spirituali quam temporali, quod idem episcopus et suum capitulum in predicto Colmensi dominio olym habuerunt [...]). Ebenso hat der Fälscher sich selbst durch den Unterschied zwischen dem ursprünglichen Text von I 222 und seinen Ergänzungen verraten, indem er entweder die Gegenwart, die Vergangenheit oder die Zukunft genutzt hat (donavi / confero / dabit). ${ }^{41}$ Kurz gesagt, habe

37 Ebd., I 8: „Die Analyse beweist, dass die Lonyzer Fälschung sich auf zwei Urkunden aus den Jahren I 222 und I 228 stützt“. Paweł Grochowski akzeptiert auch diese Hypothese (vgl. Grochowski, Chrystian, 97).

38 Jasiński, "Die Verleihung," I $о$.

39 Ebd., 4.

40 Ebd., 4.

41 Paweł Grochowski stimmt neuerding mit dieser Annahme an (vgl. Grochowski, Chrystian, 99). 
er wahrscheinlich ein "cut-and-paste“ gemacht, ohne über die Inkonsistenz des Ergebnisses nachzudenken. Weiter wäre die Vertagung der Entscheidung betreffend die Güter des Herzogs Henryk Brodaty I 222 unverständlich, aber durchaus möglich für I 228 in Skaryszew, weil damals Henryk abwesend war. Insbesondere unterstreicht T. Jasiński den außergewöhnlichen Ausdruck quondam castra. Er erinnert daran, dass „das Wort castrum in den damaligen polnischen Quellen nicht nur Befestigung, sondern vor allem Verwaltungsbezirk" bedeutet. ${ }^{42}$ War eine Befestigung zerstört, wird das Wort castrum noch gebraucht, weil es den gesamten von der befestigten Anlage kontrollierten Bezirk beschreibt. Die Anwendung des Adverbs quondam bedeutet, dass zum Zeitpunkt des Schreibens von [B], das Castrum-System des Herzogs von Masowien nicht mehr existierte. ${ }^{43}$ Er stellt fest, dass die Bestätigung des Papstes nur von castra spricht, nicht von quondam castra. So sei [B] eine Fälschung; es ist unmöglich, 1222 quondam castra zu schreiben. Der Ausdruck kann daher erst von einem späteren Zeitpunkt stammen. So sind weder [B] noch [A] die authentische Version der Urkunde von Lonyz:

„Der Unterschied zwischen den beiden Versionen des Lonyzer Vertrags auf der einen und der päpstlichen Bestätigung auf der anderen Seite ist so groß, dass es keine Möglichkeit ist, die Authentizität des Lonyzer Vertrags sowohl in Fassung A als auch in Fassung B zu verteidigen. “4 ${ }^{44}$

$3^{\circ}$ Warum würden zwei Fälschungen gemacht, und nicht nur eine? Obwohl die erste $[\mathrm{B}]$ für Konrad akzeptabel war und zur Besiegelung angeboten werden konnte, galt dies nicht für [A], aufgrund der Übertragung des Löbauer Landes, die Konrad nie akzeptiert sollen hätte. ${ }^{45}$

$4^{\circ}$ Die Exemplare $[\mathrm{A}]$ und $[\mathrm{B}]$ sind immer im Diözesanarchiv von Kulm geblieben. Da der Orden sie nie erhalten hatte, war Christian der einzige, der diese Fälschungen machen konnte. ${ }^{46}$ Beide erstellte er I 240 während seines Versuchs, sein Eigentum wiederzuerlangen, das von den Ordensrittern während seiner Gefangenschaft an sich gerissen wurde.

${ }^{42}$ Jasiński, "Die Verleihung," 5.

43 Ebd., 6: „[...] nach der Deaktualisierung des polnischen Burgensystems“.

44 Ebd., 6-7.

45 Ebd., I 9: „Wenn wir annehmen, dass Konrad tatsächlich sein Siegel an Text B gehängt hat, können wir eklären, warum Christian eine eigene Fälschung (Text B) interpolierte, wodurch Text A entstand".

46 Ebd., 8: „Bereits der Aufbewahrungsort von Fassung A weist deutlich auf den Fälscher hin“; ebd., 9: „Der Deutsche Orden kommt auch als Fälscher nicht in Frage. Nur Bischof Christian bleibt verdächtig“. 
Tomasz Jasińskis Analyse ist zugleich deutlich und konsequent. Insbesondere scheint es klar zu sein, dass der von [A] und [B] kopierte Text aus einer Fusion von zwei Texten unterschiedlicher Datierung ( 1222 und I 228) stammt, was die grammatikalische Ungeschicklichkeit und die Diskrepanz der Verben erklärt, sowie die Tatsache, dass Gedko nicht in der ersten Person spricht (da er I 223 starb, kann sich ein Dokument aus dem Jahr I 228 nur an seine vorherige Zustimmung erinnern). Aber eine ungeschickte sprachliche Gestaltung ist nicht unbedingt ein Beweis für eine Verfälschung, und einige Elemente bleiben unklar:

- In Erwägung, dass Konrad um I 228 das Kulmerland dem Deutschen Orden schenkte (und so Christian enteignete), stellt sich die Frage, warum Christian den Deutschordensbrüdern das Kulmerland (und nicht nur seine Besitztümer) zwei und drei Jahre später übergeben sollte, d. h. I 230 und I 23 I ?77 Gewiss, einen Monat nach dem Vertrag von Biecz übertrug er dem Orden am 2. Mai I 228 die im Kulmerland erhobenen Zehnten (Vertrag von Mogiła ${ }^{48}$ ). Tatsächlich hatte er keine andere Wahl, und er folgte einfach den Entscheidungen des Papstes: Honorius III. stellte I 220 eine Urkunde aus, die den Orden erlaubte, den Zehnten in den Ländern einzuziehen, in denen er sich etablieren konnte. ${ }^{49}$

- Die Stilelemente sind zufällig: viele authentische Urkunden beachten nicht die Standardformen (die Kombination von Genitiv und Ablativ und die Einfügung eines absoluten Ablativs in Bezug auf den Erzbischof von Gniezno sind Ungeschicklichkeiten und Hinweise auf die Fusion von zwei Urkunden, aber nicht unbedingt der Beweis für eine Fälschung). Die Verwendung unterschiedlicher Zeitformen findet sich in einigen Schenkungsurkunden und ist nicht immer ein Hinweis auf einen zeitlichen Unterschied zwischen jüngeren und älteren Schenkungen. In diesem Fall vermischt genau die Urkunde betreffs der Schenkung des Löbauer Landes die Verbformen von Gegenwart und Vergangenheit: quicquid est in lite de mea terra inter me et Prutenos, pro bono pacis eidem episcopo condon avi. Schließlich werden die bereits 1223 erwähnten Orte unter das gleiche zeitliche Regime gestellt wie die Orte, die dort nicht erschienen. Der Verfasser wäre hier daher in seiner vermeintlichen „Falsifikation“ weniger ungeschickt gewesen.

- Wie kann man erklären, dass [A] ( I 240) von [B] (I 264) komme? Wenn [A] den Text übernommen hat, von dem [B] das Vidimus ist, wie wäre das möglich,

47 Preußisches Urkundenbuch, I.I, hrsg. v. Philippi, 53-54 Nr. 73; 63 Nr. 82.

48 Aber dann behält er seine Rechte: [...] in his bonis que dux Masovie et Cuiavie predictis militibus salvo iure nostro licite conferre potuit, vgl. Preußisches Urkundenbuch, I.I, hrsg. v. Philipp, 48 Nr. 65.

49 Tabulae ordinis Teuthonici ex tabularii regii Berolinensis codice potissimum, hrsg. v. Ernst Strehlke (Berlin: Weidmann, I 869), 275-279 Nr. 306 (Bulle Etsi neque vom I 5. Dezember I 220). 
wenn Christian um I 240 nicht mehr über die Originale verfügte? Worauf hätte er sich für seine Fälschungen stützen können?s०

- Über den äußerst seltenen Ausdruck quondam castra meint T. Jasiński, dass dieser das Ergebnis der Auflösung des Castrum-Systems des Kulmerlands durch die Einsetzung des Deutschen Ordens sei. Aber seltsamerweise waren einige von diesen quondam castra ke in e castra in der päpstlichen Bestätigung von I223, sondern villae oder possessiones (Colno, Villisaz, Kysin und Ploth). Wurden sie denn castra und waren es dann nicht mehr, alles im Zeitraum von I 222- I228? Dies ist nicht unmöglich angesichts der militärischen Handlungen der polnischen Herzöge in den Jahren I 222-I 223 und danach, aber setzt eine rasche Ausweitung von Konrads Herrschaft voraus, insbesondere wenn das Wort castrum auf einen Bezirk verweist. Es ist jedoch durchaus möglich, dass diese Orte nach I 222/ I 223 im Zuge des Vertrags befestigt wurden. In der Tat erwähnt die Vertragsurkunde selbst die Wiederherstellung des castrum Kulm, und es ist wahrscheinlich, dass diese Sorge um die Befestigung in den folgenden Jahren angesichts der heidnischen Angriffe erweitert wurde. Es ist aber auch möglich, dass das Adverb quondam sich auf die Zerstörung oder die vorübergehende Aufgabe dieser castra wegen dieser Angriffe bezieht. Laut Piotr Miernik zeigen die archäologischen Ausgrabungen in den Jahren 2003-2008 in Pień, dass das castrum, das auf das i I. Jahrhundert zurückgeht, zur Zeit des Lonyz-Vertrags alle seine Verteidigungsfunktionen verloren hatte. ${ }^{\text {st }}$

\section{Geographie Der SCHENKUngen}

Einige der in den Versionen des Lonyz-Vertrags genannten Orte wurden von Richard Philippi oder Wojciech Kętrzyński identifiziert, bevor Krystyna Porębska das gesamte geohistorische Wissen über das Kulmerland verbesserte. ${ }^{52}$

so Perlbach, Preussisch-polnische Studien, 33, stellt die Frage: Hat Christian mehrere Versionen des Vertrags gehabt? Hat er um I 230/ I 23 I ein zweites Original behalten?

ऽ1 Piotr Miernik, "Quondam castrum Pin w świetle najnowszych badań archäologicznych," Archaeologia Historica Polona 22 (20 I 4): 69-87 (http://dx.doi.org/ I 0.1 2775/AHP.20 I 4.004).

s2 Stownik historyczno-geograficzny ziemi chetmińskiejw średniowieczu, bearb. v. Krystyna Porębska (vgl. Anm. 23). Vor dem Zweiten Weltkrieg hatte Wilhelm Heym archäologische Ausgrabungen durchgeführt, deren Ergebnisse er verloren hatte, die er aber in einem I 963 veröffentlichten Artikel auswendig (!) wiederherstellte, vgl. Wilhelm Heym, "Frühe Burgen des Kulmerlands. Ein Beitrag zu den Burgen, die im Vertrag von Lonyz 1222 »quondam castrum « genannt werden," Jahrbuch Albert-Universität zu Königsberg/Pr. I 3 ( I 963): 307-320. Einige der im Vertrag genannten Stellen zeigten in 1940 die Spuren einer Befestigung oder Besiedlung, aber ohne Möglichkeit, ihren Ursprung mit Sicherheit zu bestimmen (waren sie polnische Konstruktionen oder, wie W. Heym annahm, wurden sie von Christian von Preußen selbst errichtet?). Die 
Die begrenzte Schenkung von 1222 steht im Einklang mit dem Rand des Gebietes, das damals - etwa mit Mühe - von den polnischen Herzögen kontrolliert wurde. Sie erweiterte Konrads erste Schenkungen an Christian (wahrscheinlich rund um Kulm) im Jahr I 2 I9. Der Herzog konnte nur wenige castra geben und konnte sich nicht weit vom rechten Ufer der Weichsel entfernen, mit Ausnahme von einem castrum und einem Gebiet 25 und $30 \mathrm{~km}$ von Kulm am Rande der von den Prußen kontrollierten Gebiete (Copriven und Velsaz). Es ist daher sehr wahrscheinlich, dass $[\mathrm{P}]$ ein wahrheitsgetreues Bild vom wirklichen Geschenk der polnischen Fürsten im Jahre I 222 gibt: eine kleine Anzahl von schlecht befestigten Gütern an der Weichsel, mit zwei Außenposten gegenüber den heidnischen Gebieten. Alle sind die Zeugen der christlichen Siedlung, die seit einigen Jahren in der Region stattfand.

Wenn man die geographische Lage der I I gemeinsamen castra von [A] und [B] prüft, sieht man, dass alle sich am rechten Weichselufer oder wenige Kilometer östlich (Graudenz, Copriven, Wabsk, Colno, Rudas ${ }^{s 3}$ Kysin, Pin, Ploth - nur Villisaz östlich von Kulm und Glamboki nördlich von späteren Thorn (poln. Toruń) sind Außenposten) befinden. Der Gestalt des gesamten Gebiets ist ein sehr langes Viereck von Nord nach Süden (in dem sich auch die Dörfer Bolemyno und Scarnese befinden - nur Mirche wäre weiter östlich, aber seine Lage ist ungewiss), in der westlichen Hälfte des Kulmerlands. Der Besitz des Bischofs von Płock sollte unweit der Südgrenze von Kulmerland liegen. Die anderen gemeinsamen Grundstücke von [A] und [B] (Gruth-Wald, die Ländereien bei späteren Kulmsee) befinden sich im gleichen Gebiet, einige mal etwa weiter östlich und südöstlich, aber immer in der westlichen Hälfte des Kulmerlands (siehe Tabelle und Karte) innerhalb des Perimeters der Linien zwischen heutigen Grudziądz (Graudenz), Radzyń Chełmiński (Rehden), Chełmża (Kulmsee), Fordon (Fordun) und der Weichsel. Deren Besitz sollte Christian als Grundherr des Landes die notwendigen natürlichen Ressourcen und Steuereinnahmen (insbesondere den GruthWald) verschaffen.

Andererseits liegen die I 2 Befestigungen, die nur in der Fassung von I $238-$ - I 240 ([A]) erwähnt werden, viel weiter östlich. Drei von ihnen (Kovalevo, Ostro-

Ausgrabungen von 1974-1976 zeigten die Existenz von Befestigungen in Pokrzywno bevor der Ankunft des Deutschen Ordens, vgl. Tomasz Torbus, Die Konventsburgen im Deutschordensland Preußen, Schriften des Bundesinstituts für ostdeutsche Kultur und Geschichte I I (München: R. Oldenbourg, 1998), 73.

53 Andrzej Janowski schlägt vor, Ruth liege neben Sarnowo (alias Rutenberg) i 9 km östlich von Kulm und nicht neben Grudziądz, vgl. Andrzej Janowski, "Quondam castrum Ruth - proba lokalizacji średniowiecznego grodu w ziemi chełmińskiej w świetle źródeł pisanych i archeologicznych," Archaeologia Historica Polona 17 (2007): 278-292. 
vith, Colman) bilden ein Dreieck an der Grenze zum Dobriner Land. Die acht anderen zeichnen einen „limes“ am Rande des Löbauer Landes und verbinden die Osa mit dem Michelauer Land (das ist besonders deutlich für sieben von ihnen; nur Osechino (heute Osieczek) liegt etwa $8 \mathrm{~km}$ weiter im Landesinneren). Entweder hat Christian eine Fälschung gemacht, um sich ein gut geschütztes Gebiet zu schaffen, oder er will die in seinem Auftrag gebauten castra zurücknehmen in einem Gebiet, das er seit I 2 I 6 besaß und das ihm Konrad I 228 anerkannt hatte.

\section{Hypothesen ÜBeR die FASSUngen}

Gehen wir zu den Vidimus zurück und untersuchen wir ihre möglichen Beziehungen. Wir wissen, dass $[\mathrm{A}]$ und $[\mathrm{B}]$ in vier Punkten sich unterscheiden: ${ }^{54}$

- vier der in $[\mathrm{B}]$ genannten Dörfer finden sich nicht in $[\mathrm{A}]$; zwei wurden als castra präsentiert;

- [A] erwähnt I o castra, die nicht mehr in [B] erscheinen;

- [A] bezieht sich auf Konrads Schenkung eines Bezirks, der mit den Prußen umkämpft war, und von dem $[\mathrm{B}]$ nichts sagt;

- [A] spricht über ein episcopus Prutie, während [B] den Bezug zu Preußen aufgibt.

Max Perlbach widerlegte R. Philippis findige Hypothese: der Meinung R. Philippis nach, entsprachen die zwei größten Lücken jeweils 87 Buchstaben, d. h. eine ganze Zeile, daher vertrat er die Annahme, dass der Kopist von I 264 diese beiden Zeilen versehentlich weggelassen habe.5s Aber diese Lösung basierte auf der gedruckten Ausgabe, ohne die Abkürzungen der Urkunden selbst zu berücksichtigen. ${ }^{66}$ Solche eine Unachtsamkeit war umso unglaublicher, als beide Abschriften von [B] sie aufweisen. M. Perlbach zeigte jedoch durch einen Vergleich, dass die zwei Fassungen dasselbe Original abgeschrieben hatten: ${ }^{57}$ der Schreiber (oder die

\$4 Wir berücksichtigen die Rechtschreibunterschieden nicht, z. B. wo [A] die Schreibweise Prutia oder Pruzia und Zlesie verbraucht, bzw. [B] Pruscia und Slesie. Für viele Orten verwendet [B] den Buchstaben , $z^{\text {' }}$, vs. , $c^{\prime}$ in $[A]$. Offensichtlich waren die Autoren oder Schreiber von [B] germanischer Herkunft, und die aus einer [A] lateinischer Schrift- und Oralkultur, vgl. Perlbach, Preussische-polnische Studien, 30-3 I, für alle Varianten.

ss Diese Hypothese wird von Carl Peter Woelky wiederaufgenommen, vgl. Urkundenbuch des Bisthums Culm, I.2, hrsg. v. Woelky, 667 Nr. 803.

56 Perlbach, Preussisch-polnische Studien, 3 I -32. Er schätzt auf 82 und 54 die jeweilige Anzahl der Buchstaben in den beiden weggelassenen Pasagen.

57 Perlbach, Preussisch-polnische Studien, 32: „In zwei Exemplaren aber wurde der Lonyzer Vertrag (nur dieser) erneuert, weil das Original anscheinend nicht mehr in gutem Zustande sich befand“. 
Schreiber) hätte dieselben beiden Lesefehler machen sollen, was höchst unwahrscheinlich ist. ${ }^{58}$

Um den Ursprung der Elemente zu erklären, die für [A] und [B] spezifisch sind, müssen wir die in der Einleitung vorgeschlagenen Hypothesen noch betrachten. Wir haben die Hy p o th e se 2 beseitigt, d. h. dass [B] von [A] abstamme und es modifiziert hätte, weil der Vidimus von Anselm eine Urkunde, nicht ein anderes Vidimus, beglaubigt hat. Also bleibt nur die Hypo the se I: [A] und B] stammten vom gleichen Text ([L'] - der freillich die $[A]$ und $[B]$ gemeinsamen Elemente enthielt) und modifizierten ihn. [B] könnte also einen Text verkürzt und aktualisiert haben, vom welchen [A] ein wahrheitsgetreues Bild gebe. [A] könnte die Schenkungen erweitern, entweder auf betrügerische oder legitime Weise. Daher ist es notwendig, die fraglichen Elemente zu untersuchen.

$I^{\circ}$ Die Umwandlung von episcopus Prutie in einen episcopus.

Zwischen I 222 und I 243 gab es nur einen „Bischof von Preußen“. Wenn Christian der Autor von $[\mathrm{B}]$ wäre und es gefälscht hätte, warum würde er diesen Titel entfernen, und dann in $[\mathrm{A}]$ wiederverwenden? Andererseits war die Erwähnung I 264 obsolet, da Preußen seit I 243 in vier Diözesen unterteilt war. Die Erwähnung eines episcopus und nicht eines episcopus Prutie in [B] ist daher ein starker Hinweis auf die Aktualisierung des I 264 abgeschrieben Dokuments.

$2^{\circ}$ Der Fall der Dörfer, die sich in [B] und nicht in [A] finden (Plomzino und Clezchowar). ${ }^{59}$

Wenn wir die Hypothese einer Auslassung des Kopisten von [A] ausschließen, ist ihre Anwesenheit in [B] eine Ergänzung, die durch die Gründung dieser zwei Dörfer in der Zwischenzeit erforderlich wurde. Es ist möglich, dass der neue Bischof von Kulm sie anlässlich der Abschrift einschieben ließ. Die Hypothese ist plausibel angesichts des Ausbaus der ländlichen Siedlung im Kulmerland in der zweiten Hälfte des I 3 . Jahrhunderts.

$3^{\circ}$ Der Fall der zwei in [A] zitierten castra, welche zu villae in [B] gewandelt wurden (Postolsco und Ostrovith).

Die Statusänderung könnte durch die Veränderungen im Netz von Befestigungen im Kulmerland erklärt werden, da die Deutschordensbrüder seine Kontrolle allmählich übernahmen. [B] würde daher eine Version geben, die der Situation von I 264 und nicht der von I 222/ I 228 entspricht.

$4^{\circ}$ Der Fall der 10 castra, die in $[\mathrm{A}]$ und nicht in $[\mathrm{B}]$ genannt sind, und die Schenkung des Löbauer Lands.

58 Ebd., 3 I-32.

59 Pomzino (heute Pędzewo) würde sich $17 \mathrm{~km}$ südwestlich von späteren Toruń befinden und Clezchowar (Klęczkowo) I 2 km südwestlich von Grudziądz. 
Dieser Punkt ist der heikelste. Wenn sie in die ursprüngliche Urkunde von I 228 aufgenommen wurden, wären sie folglich in I 264 gelöscht worden. Aber warum? Wenn sie nicht I 228 aufgenommen wurden, muss man verstehen, warum Christian sie I 240 eingefügt hat und ob er dabei betrügerisch gehandelt hat.

Wurden diese castra und das Löbauer Land um I 228 von Konrad geschenkt, oder versuchte Christian es so glaubwürdig erscheinen zu lassen? I 228 kontrollierte Konrad diese Gegend nicht. Gab es dann schon an der Grenze mit dem Löbauer Land einen „limes“ von Befestigungen? Das scheint ein wenig zu früh zu sein außer wenn Christian sie zwischen I 2 I 6 und I 228 bauen ließ; dieser Anlass bleibt aber ungewiss. Wäre es der Fall, so wäre Christian berechtigt, sie I 240 einzufordern. Andernfalls müssen wir zugeben, dass es sich um eine Interpolation von ihm handelt, was die meisten Historiker auch ahnen.

In diesem Fall muss noch entschieden werden, ob es eine berechtigte Forderung war (durch Schenkungen oder Übernahmen) oder eine betrügerische Handlung. Christian wollte sich offensichtlich auf diese Linie von castra und die Herrschaft über das Löbauer Land stützen, um im Jahr I 240 seine Position im Konflikt mit dem Orden zu stärken. Die Verdichtung half der Landesherrschaft. Um I 23 I musste er das Kulmerland dem Deutschen Orden abtreten (doch bewahrte er seine bischöflichen Rechte und Besitztümer), aber der Vertrag erwähnt nicht das Löbauer Land und gibt keinen Hinweis darauf, dass Christian es an diesem Tag dem Orden übergeben hätte. ${ }^{60}$ I 233 wurde er von den Heiden gefangen, bis I 238. Dann beschuldigte er den Orden einer Usurpation, versuchte sein Eigentum zurückzugewinnen und erhielt die Unterstützung des Papstes, der um I 240 eine Untersuchung anordnete. ${ }^{6}$ Ein starkes Indiz dafür ist die Tatsache, dass das in I 5 I 4 in [E] beschriebene Vidimus 9 Siegel erwähnte, darunter die von drei sächsischen Bischöfen (Meißen, Naumburg und Merseburg): tatsächlich, wie T. Jasiński es sah, beauftragte Gregor IX am I I. April I 240 den sächsischen Klerus mit der Untersuchung. ${ }^{62}$ Der Papst betont, Christian solle die Güter genießen können, die er brauche (beneficiis oportunis provides de circumspectione solita). So hätte Christian $[\mathrm{A}]$ aufsetzen lassen, um sich dem Orden widerzusetzen.

War er der rechtmäßige Eigentümer alles, was er beanspruchte? Was das Löbauer Land betrifft, so erscheint die Antwort positiv. Zwar ist [A] für die meisten Historiker ein gefälschtes Dokument, und die Elemente, die es als einziges enthält, beweisen es. Es gibt jedoch ein Detail, das in die Gegenrichtung weisen könnte:

60 Preußisches Urkundenbuch, I. I, hrsg. v. Philippi, 63 Nr. 82.

${ }_{61}$ Ebd., I $~$ I Nr. I 34: Prefatam vero terram Culmensem contra predictas pactiones iuramento firmatas detinent totaliter occupatam, iura episcopalia usurpantes in preiudicium ecclesie Pruscie et ipsius non modicam lesionem.

62 Jasiński, "Die Verleihung," 9. 
der Ausdruck pro bono pacis, der die Schenkung des Löbauer Landes rechtfertigt. Um welchen Frieden geht es hier? Der Text erwähnt den Konflikt zwischen Konrad und den Heiden, und die gesamte nachfolgende Geschichte zeigt, dass die Herzöge von Masowien die Region beansprucht haben: zwischen I 242 und I 257 schlossen sie und der Deutsche Orden mehrere Verteilungsverträge. ${ }^{63}$ In diesem Fall: warum sollte der Herzog 1228 dem Bischof diese Gegend überlassen haben? Es wäre ein vergiftetes Geschenk, weil Christian zu dieser Zeit keine militärische Kraft hatte und daher nicht über die Mittel verfügte, das Gebiet zu kontrollieren. Aber hier sei es daran erinnert, dass Christian dieses Land 2 I 6 vom heidnischen Survabuno erhalten hatte - mit einer Bestätigung von Papst Honorius III. ${ }^{64}$ Also gehörte es ihm. Es wäre daher denkbar, dass Konrad dieses Land I 228 gab, um dieses Geschenk zu respektieren und einen Konflikt zwischen ihm und dem Bischof zu vermeiden,.

Man kann jedoch nicht ausschließen, dass der Bischof kunstvoll ein herzogliches Geschenk glauben machen wollte - so ahnt es T. Jasiński. Eine Bestätigung von Konrad war wertvoller als das einzige Geschenk eines Heiden; die Formel pro bono pacis wäre dann eine Rechtfertigung. Damit wäre die Herrschaft des Bischofs unveräußerlich, da die Deutschordensbrüder das Land der Prußen nach Belieben erobern konnten, aber nicht die Ländereien der Heiden, die sich spontan bekehrt hatten, woran die Päpste erinnerten. ${ }^{65}$ Auf jeden Fall konnte Christian um I 240 durch die Rückeroberung des Löbauer Landes auch hoffen, sich dort außerhalb der Herrschaft des Deutschen Ordens niederzulassen.

Der wichtige Punkt ist: hielt Christian I 240 dieses Land oder einen Teil davon de jure? Es ist bekannt, dass Wilhelm von Modena am I I. Februar I 240 zwischen dem Deutschen Orden und Konrad schlichtete: der Herzog beschuldigte die Deutschordensbrüder, seine Rechte in der Region verletzt zu haben. Er gab zu, dass das Löbauer Land ein Teil Preußens war, aber er beanspruchte es, weil es

${ }_{63}$ Urkundenbuch des Bisthums Culm, I.I, hrsg. v. Woelky, 3 Nr. 7 (Urkunde vom 20. September I 242); 22-23 Nr. 36[A.] und 36[B.] (Urkunden von 25-31.Dezember I 254); 34-35 Nr. 50[A.] und 50[B.] (Urkunden vom 4. August I 257).

${ }_{64}$ Preußisches Urkundenbuch, I. I, hrsg. v. Philippi, 7 Nr. 9 (Urkunde vom I 8 . Februar I 2 I 6).

65 Es gibt ein direkter Beweis dafür, am I9. Mai I 253, als die Brüder die Absicht anzeigten, das Land der Polexianer zu erobern. Da sie sich spontan bekehrt und sich unter Kazimierz von Kujawien überzogen, verbot der Papst dem Orden, ihr Land zu nehmen, obwohl es zu Preußen gehörte, vgl. Preußisches Urkundenbuch, I.I, hrsg. v. Philipp, 203 Nr. 267): Non obstante, quod fratribus domus Theutonicorum tota terra Pruscie, quam gladio sibi subingare poterint, dicitur esse ab apostolica sede concessa, cum sponte, non coact gladio, velint ipsi pagani, ut dictum est, ad fidem christiani nominis convolare. 
die Herzöge von Masowien militärisch erobert hatten. ${ }^{66}$ Am 20. September 1242 wurde ein Vertrag zwischen dem Landmeister Heinrich von Wida und Konrad geschlossen: der Orden übergab dem Herzog die Hälfte von zwei Dritteln der Gegend ${ }^{67}$ Diese Vereinbarung bewahrt die ordinatio olim celebrata durch Wilhelm von Modena zwischen den Brüdern und Christian: der Bischof hatte ein Drittel aus der Region erhalten, und die Deutschordensbrüder den Rest davon. Der Zeitpunkt dieser ordinatio lag allerdings nach dem Februar I 240 und vor der Abreise von Wilhelm von Modena, der Preußen am i 9. April i 242 verließ, was bedeutet, dass Christian dann einen Teil des Löbauer Landes hielt (oder zumindest Rechte daran hatte). ${ }^{68}$ Nach seiner vollständigen Überlassung des Kulmerlands I23 I wurde daher ein neuer Vertrag zwischen dem Orden und dem Bischof über das Land Löbau geschlossen. ${ }^{69}$ In diesem Fall kann [A] nicht als ein vollständiges Falsifikat angesehen werden. Die Bischöfe von Kulm blieben von dieser Region angezogen. Als Wilhelm von Modena I 243 Preußen in Bistümer teilte, schloss Kulm die Gegend Löbau ein (ita quod in eadem diocesi

66 Ebd., 99-1 00 Nr. I 32: Confitebantur autem autem ibidem duces predicti, quod terra de Lubowe fuit und ist von terminis Pruscie, sed pertinebat ad eos, quia parentes eorum et ipsi acquisissent eam de manibus Prutenorum cum gladio et clipeo suo.

${ }_{67}$ Ebd., I03-I 4 Nr. I39 (= Urkundenbuch des Bisthums Culm, I.I, hrsg. v. Woelky, 3 Nr. 7).

68 Marc Löwener, Die Einrichtung von Verwaltungsstrukturen in Preußen durch den Deutschen Orden bis zur Mitte des I3. Jahrhunderts, Deutsches Historisches Institut Warschau. Quellen und Studien 7 (Wiesbaden: Harrasowitz Verlag, I 998), 95-98, datiert diese Vereinbarung bevor September I 233, aber angesichts des Briefs von Gregor IX. vom I I. April I 240 (in dem der Streit zwischen dem Bischof und dem Orden besprochen wird und wo kein Bezug auf die Teilung des Kulmerlands hergestellt wird), ist es lieber zwischen dem I 2. April I 240 und dem 19. April I 242 (Datum der Abreise von Wilhelm von Modena aus Preußen). I 25 I bestätigte Wilhelm von Modena die Existenz dieser Verteilung, vgl. Preußisches Urkundenbuch, I.I, hrsg. v. Philippi, 174 Nr. 238.

69 Es handelt sich wahrscheinlich um den Vertrag, der am 19. April I 246 vom Hochmeister Heinrich von Hohenlohe auf Ersuchen des Bischofs von Kulm Heidenreich bestätigt wurde (Bestätigung bekannt durch eine zweite Bestätigung vom I 5 . Juni I 298, vgl. Urkundenbuch des Bisthums Culm, I. I, hrsg. v. Woelky, 5-6 Nr. I 4). Die Historiker sind sich darüber nicht einig, ob diese Verteilung nur das Löbauer Land oder das Kulmerland oder sogar Preußen betraf. Nach M. Löwener wurde „dem Bischof [...] im Gegensatz zu den preußischen Diözesen nicht ein Drittel des Landes überlassen, vielmehr sollte er hier [...] von jedem Pflug ein Mass Weizen und ein Mass Roggen, von jedem Haken ein Mass Weizen, ausserdem sechshundert Hufen erhalten“, vgl. Löwener, Die Einrichtung, I 03; im Gegenteil spricht G. Labuda: „Die neue Aufteilung betraf ganz Preussen, nicht nur dessen kleineren Teil; ähnlich verhielt es sich mit dem Kulmerland", vgl. Gerard Labuda, "Entstehung und Entwicklung des Deutschordensstaates in Preußen." in Gerard Labuda und Marian Biskup, Die Geschichte des Deutschen Ordens in Preußen: Wirtschaft, Gesellschaft, Staat, Ideologie, übersetzt v. Jürgen Heyde und Ulrich Kodur (Osnabrück: fibre Verlag, 2000), i I 5-290, hier I 45, Anm. 35. 
Lubovia includatur)..$^{70}$ Am 22. Juli I 25 I übergab der Bischof von Kulm, Heidenreich, seinen Chorherrn 600 Hufen und einige villae im Löbauer Land, was sein Nachfolger Friedrich am I. Februar I 264 bestätigte. ${ }^{71}$ Am I 2 . März I 255 ermächtigte Papst Alexander IV. den Bischof von Kulm, Besitzungen in der Region von Löbau zu belehnen, weil diese, obwohl christlich, immer von den Heiden bedroht waren. ${ }^{72}$ Schließlich gewährte der Landmeister Hartmud von Grumbach dem Bischof von Kulm I 260 den Besitz eines Teils des Landes Löbau im Austausch für ein anderes Gebiet; in dieser Weise beendete er den Streit zwischen dem Orden und dem Bischof, der dieses Land von Herzog Kazimierz gekauft hatte, gegen den Willen des Ordens:

[...] quas postmodum tempore procedente venerabilis pater noster episcopus Culmensis ab ipso [Casimiro duce] emittieren, nobis contradicentibus et invitis, ex qua emptione nobis reputavimus esse non modicam iniuriam irrogatam, licet ipsi dominino episcopo contrarium videretur. ${ }^{73}$

$5^{\circ}$ Letztlich haben wir den Fall der I 2 castra, die nur [A] erwähnt.

Nur zwei sind noch als Befestigungen im letzten Viertel des I 3. Jahrhunderts belegt und gehören zum Orden: Kowalewo (dt. Schönsee) wurde eine Komturei, und Płowęż (dt. Plowenz) (als castrum feodatarii) wird von Peter von Dusburg bei seiner Belagerung von den Jatwingern 1277 erwähnt. ${ }^{74}$ Acht dieser castra werden Dörfer, und am Ende des 13. Jahrhunderts befinden sich sieben in den Händen von preußischen Bischöfen. Ostrovoth und Postolsco werden I 264 als

70 Preußisches Urkundenbuch, I. I, hrsg. v. Philippi, I08-ı о9 Nr. I43. Wenn man den Text von Wilhelm von Modena liest, sieht man, dass er die gleiche $2 / 3-1 / 3 / 3$ Teilung festlegt, wo es nur ein Bischof geben wird (also im Löbauer Land, das ein Teil des Kulmerlands ist) und wo es mehrere geben wird (Preußen, in drei Diözesen unterteilt): ita quod, sive unus episcopus fuerit, sive pleures; episcopo vel episcopis qui pro tempore in Pruscia und eadem terra Culmensi fuerint $[\ldots]$.

${ }_{71}$ Urkundenbuch des Bisthums Culm, I.I, hrsg. v. Woelky, 17 Nr. 29 (Schenkung der villae von Raczlai, Hermannistorp und Arnoldestorp); 49-50 Nr. 72 (Schenkung vom allodium von Belczin).

72 Ebd., 30 Nr. 44: Licet Terra Lubowie [...] sit de novo ad cultum nominis christiani conversa, non potest tamen a vicinis defendi paganis [...] sed potius deserta permanentet [...].

73 Ebd., $43-44$ Nr. 59.

74 Petrus de Dusburgk. Chronicon terrae Prussiae, hrsg. v. Jarosław Wenta und Sławomir Wyszomirski, Monumenta Poloniae Historica. nova series XIII (Kraków: Polska Akademia Umiejętności, 2007) I74, pars III, cap. I 92. 
Dörfer erwähnt. ${ }^{75}$ Belyz ${ }^{76}{ }^{6}$ Bobrofh ${ }^{77}$ und Neuyr ${ }^{78}$ gehören dem Bischof von Kulm; Colman, ${ }^{79}$ Mylesevo $^{80}$ und Ostrovithe dem Bischof von Kujawien; Jablovo liegt im Bereich des Ordens. ${ }^{8}$ Osechino und Wanzino scheinen keine Spuren hinterlassen zu haben. Diese Verwandlung kann man erklären durch das Ende der militärischen Gefahr und den Bau eines neuen Burgennetzes durch den Orden. Sie wurden wahrscheinlich um I 240 von Christian errichtet und spielten I 264 keine Rolle mehr. Es ist nicht unmöglich, dass diese castra aufChristians Befehl vor I 233

75 Ostrovith/Ostrowite erscheint als villa in einer Urkunde (I 258 ) des Hochmeisters Gerard von Hirschberg, die den Verkauf an Bischof Michael von Leslau erinnert, nach der Ernennung des Komturs von Christburg Heinrich Stange und vor dem Tod des Bischofs Michel, d. h. zwischen I 248 und I25, vgl. Preußisches Urkundenbuch. Politische (allgemeine) Abteilung, Bd. I, Die Bildung des Ordensstaats, Hälfte 2, bearb. v. August Seraphin (Königsberg/Pr.: Hartungsche Verlagsdrückerei, I 909), 53-55 Nr. 60.

${ }^{6}$ In I 25 I wird Belyz als grangia mit dem Namen Sconenwerde, gewahrt, vgl. Urkundenbuch des Bisthums Culm, I.I, hrsg. v. Woelky, 17 Nr. 29 [A. und B.]. Bischof Heidenreich stattet sein Domkapitel mit 600 Mansen im Löbauer Land aus: Conferimus ei villam Razlay und villam Hermannysdorp, und villam Arnoldisdorp, und grangiam Sconenwerde cum villula adiacente [...]. Es scheint, dass Belyz ziemlich früh ein Dorf und das Zentrum eines Bauernhofes wurde. Die Identifizierung zwischen Belyz und Sconenwerde wird durch ein Gesetz von I 264 vorgeschlagen, mit dem der Bischof von Kulm Friedrich die Ausstattung von I 25 I bestätigt, und in der Liste der ausgewiesenen Besitzen grangiam Sconenwerde mit allodium Beleczin ersetzt, vgl. ebd., 50 Nr. 72.

77 Am I 9. April I 246 übergab Hochmeister Heinrich von Hohenlohe 600 Hufen, einige davon in der Nähe von Boberow, an den Bischof von Kulm im Rahmen eines Vertrags mit Christian von Preußen, ebd., 5-6 Nr. I 4. Am 22. Juli I 25 I gründete der Bischof Heidenreich von Kulm eine Stiftskirche in Bobrowo, vgl. ebd., I Nr. 29[A. und B.].

${ }^{78}$ Juli 1248 befanden sich unter den Zeugen einer Urkunde zwei cives von Neuyr/Nebere, vgl. Preußisches Urkundenbuch, I. I, hrsg. v. Philippi, I 43 Nr. 206; einer von ihnen ist I 25 I noch Zeuge bei der Erneuerung der Kulmer Handfeste, vgl. ebd., I 92 Nr. 252, wo er als feodalis bezeichnet wird. Neuyr wird in einem I 340 Dokument vom Hochmeister Dietrich von Altenburg als „Dorf“ bezeichnet, der es abgetreten hat, vgl. Preußisches Urkundenbuch, Bd. III, Lief. I, I335-I34I, hrsg. v. Max Hein (Königsberg/Pr.: Gräfe und Unzer, I 944), 225 Nr. 323 ).

79 Am 24. Juni 1258 bestätigte Hochmeister Gerhard von Hirschberg, dass das „Dorf“ Colman dem Bischof Wolimir von Włocławek gehört, laut einer früheren Vereinbarung mit dem Hochmeister Poppo von Osternoe (1252-1256), vgl. Preußisches Urkundenbuch, I.2, hrsg. v. Seraphin, 53-55 Nr. 60. Am 28. April 1276 übergab der Bischof Albert von Leslau das Dorf Colman an zwei Männer, vgl. ebd., 234-236 Nr. 349.

8o Am I 3. Juni I 262 wird Mylesewo unter den Dörfern erwähnt, die Kazimierz von Kujawien dem Bischof Wolimir von Włocławek errichten erlaubt, und von jeglichen Dienstleistungen oder Steuern befreit, vgl. ebd., I 36 Nr. I 64: [...] ab omni servitio et solutione et ab exactione qualibet perpetuo sint liberi.

8I Bei 295 gilt es als Abgrenzung: Meinhard von Querfurt schenkt einem Mirogniw Besitze neben das Dorf Bilzen; er zitiert die villa von Gabilnaw als Abgrenzung, vgl. ebd., 4 I I-4 I 2 Nr. 650. 
gegründet wurden. Ab 1223 hatte der miles Cristianus dem Bischof sein Vermögen geschenkt, mit der Zustimmung der polnischen Herzöge (Konrad von Masowien, Leszek von Kleinpolen, Świętopełk von Gdańsk (Danzig), Henryk Brodaty von Schlesien ${ }^{82}$. Diese Schenkung fand in Anwesenheit des Kreuzritterheeres statt (coram omni exercitu crucesignatorum crucesignatorum), wie die Liste der Zeugen es beweist, mit allen polnischen Herzögen und den Bischöfen Wawrzyniec von Schlesien und Wawrzyniec von Lebus. Folglich waren die kriegerischen Handlungen noch im Gange, was wahrscheinlich die Erneuerung der castra einschloss. Der Orden hatte keinen Grund, Kowalewo und Płowęż in die Liste der Vidimus einzuschließen (oder sie aufrechtzuerhalten, wenn sie im Original genannt sind, was unwahrscheinlich ist). ${ }^{83}$

\section{FAZIT ÜBER DEN VIDIMUS}

Erinnern wir uns an die zwei Hypothesen, die oben formuliert wurden:

- Hypothese г a: [A] hat neue Elemente in den Text [L'] hinzugefügt und [B] hat ihn aktualisiert.

- Hypothese r b: [A] steht im Einklang mit Konrads tatsächlicher Schenkung im Jahr I 228, so dass [B] die Urkunde aktualisiert und auch Elemente bezüglich des Löbauer Landes entfernt hat.

82 Diese sind seine unidentifizierbaren Besitze von Tarchomino und Grodcowo, die dem Heiligen Kreuz und der sancte crucis et beate Marie Virgini in Preußen gewidmet sind, vgl. Preussisches Urkundenbuch, I. I, hrsg. v. Philippi, 34 Nr. 46.

${ }_{3}$ [A] bescheinigt die Existenz vom castrum von Kowalewo in I 240. Es ist sehr wahrscheinlich, dass es um I 230 noch nicht existierte. I 264 ist Kowalewo im Bereich des Ordens, und I 274 wird es eine Komturei: Schonese edificatum est, vgl. "Franciscani Thorunensis Annales Prussici (94I-I 4 I o)," hrsg. v. Ernst Strehlke, in Scriptores rerum Prussicarum. Die Geschichstquellen der preußischen Vorzeit bis zum Untergange der Ordensherrschaft, Bd. III, hrsg. v. Theodor Hirsch, Max Toeppen und Ernst Strehlke (Leipzig: S. Hirzel Verlag, I 866); 6I; ein Komtur Rudolf ist 278 erwähnt, vgl. Preußisches Urkundenbuch, I.2, hrsg. v. Woelky, 250 Nr. 366 . Peter von Dusburg erwähnt seine Belagerung durch die Heiden während des zweiten Glaubensabfalls, an einem ungenauen Datum, wahrscheinlich um I265-1270, vgl. Johannes Voigt, Geschichte Preußens von den ältesten Zeiten bis zum Untergang der Herrschaft des Deutschen Ordens, Bd. III, Die Zeit vom Frieden I249 bis zur Unterwerfung der Preußen I283 (Königsberg: Verlag der Gebrüder Bornträger, I 828),_297, Anm. I. J. Voigt bezieht sich auf Peter von Dusburg („c. I57“), tatsächlich c. I 62, und er zitiert Caspar Schütz, der Schönsee unter den von den Heiden zerstörten Festungen erwähnt, vgl. Caspar Schütz, Historia rerum prussicarum (Zerbst: Schmid, I 592), 37 - aber die angegebene Seite enthält keine Liste. Peter von Dusburg spricht von plura castra aber nicht nämlich von Schönsee (Kowalewo), vgl. Petrus de Dusburgk, hrsg. v. Wenta und Wyszomirski, I 5 5, pars III, cap. I62. 
Dann müsste man zugestehen, dass Konrad 1228 diese Gegend und ihre castra verliehen hatte. [B] hätte sie entfernt, mit dem Zweck, sie aus dem Zuständigkeitsbereich des Bischofs von Kulm herauszuholen. Aber das ist zweifelhaft: da der Bischof von Kulm und seine Chorherren Mitglieder des Ordens waren, wäre diese Vorsichtsmaßnahme wenig nützlich. Außerdem wäre es nicht verständlich, dass gleichzeitig darauf geachtet wurde, die zwei zu Dörfern gewordenen castra zu erfassen. Kurz gesagt: die Tatsache, dass eine Herausnahme mehrerer Elemente I 264 unwahrscheinlich ist, reduziert die Möglichkeit, dass [A] ein wahres Bild von [L'] sein könnte.

So scheint es möglich zu dem Schluss zu kommen, dass [A] den Inhalt der Urkunde von $\mathrm{I} 228$ [L'] geändert hat, von der [B] ein aktualisiertes, aber genaueres Bild gibt.

So lassen sich einige Unterschiede zwischen $[\mathrm{A}]$ und [B] durch die Entwicklung der Situation erklären und entsprechen einer Aktualisierung der vidimierten Urkunde. Andere beziehen sich höchstwahrscheinlich auf eine Einmischung des Bischofs Christian. Die Urkunde [L'], die Konrad angeblich I 228 an Christian gegeben hatte, wurde anlässlich der zwei Vidimus überarbeitet, aber das stellt keine Fälschung dar. ${ }^{84}$ Die Änderungen von [B] sind unbedeutend: mit dem Vidimus des Legaten Anselm handelt es sich nicht um eine falsche, sondern eine aktualisierte Urkunde; der Deutsche Orden nimmt dabei kein Land für sich in Besitz. Was Christian in [A] beansprucht, könnte ihm tatsächlich gehören. [A] ist daher keine Fälschung im Sinne eines betrügerischen Textes (da sein Inhalt korrekt scheint), sondern eine „Kanzleifälschung “ (Konrad könnte wahrscheinlich keine Urkunde mit dem gleichen Inhalt ausstellen haben).

\section{SZENARIOVORSCHLAG:}

I. 1222 erhielt Christian in Lonyz von Konrad und Gunther, Bischof von Płock, einige Ländereien in West-Kulmerland, in der Nähe von Kulm, Graudenz und dem späteren Thorn. Er hielt auch, de iure aber nicht unbedingt de facto,

${ }_{4}$ Die Zeugenliste ist uns keine große Hilfe. Die palatini et castellani erscheinen in einigen Urkunden in den Jahren I 223-I 224, vgl. Codex diplomaticus et commemorationum Masoviae generalis, I, Obejmujacy materyat do zgonu Konrada I, hrsg. v. Kochanowski, 233-234 Nr. 225; 238 Nr. 229; aber 1227-I 228 triftt man nur in den Akten der masowischen Kanzlei der Kanzler Gothard und der palatinus Masoviae Arnold, vgl. ebd., 272 Nr. 254; 283 Nr. 264. Folglich scheint die in $[\mathrm{A}]$ und $[\mathrm{B}]$ bewahrte Zeugenliste den anwesenden Zeugen 1222 entsprechen und sie wurde nicht im Jahre I 228 bei der Gelegenheit der Abfassung einer neuen Urkunde aktualisiert. 
die Schenkungen von I 2 I 6 und I 2 19. Diese Gebiete waren den heidnischen Angriffen ausgesetzt, aber sie waren teilweise von Christen bevölkert und etwa verteidigt. I 223 bestätigte Honorius III. den Vertrag von Lonyz.

2. Zwischen I 222 und I 228 erhielt Christian zusätzliche Besitzungen im Kulmerland, die von Konrad oder seinen Lehnsleuten gegeben wurden. ${ }^{85}$ Juni I 227 erhielt er von Gregor IX. die Bestätigung der Schenkungen von „Herzog Konrad von Masowien und Kujawien“" ${ }^{86}$ Er besitzt also zu diesem Zeitpunkt alle 1222 erhaltenen Besitzungen. I 228, wahrscheinlich als er in Skaryszew den Herzog traf, erhielt er von ihm als Entschädigung für den Verlust des Kulmerlands eine neue, erweiterte Version des Vertrags ([L']), in der alle seine aktuellen Besitzungen auflistet wurden. Diese waren hauptsächlich Landgebiete, die ihm das nötige Einkommen einbrachten. Es scheint unmöglich, dass Christian I 240 [A] aus dem Gedächtnis gefasst haben könnte, ohne die Urkunde von $\mathrm{I} 228$ vor sich zu haben.

3. Diese Version [L'] wurde als Grundlage für die Abschriften von I 240 und I 264 verwendet. Die Schenkung von Konrad spiegelt sich - größtenteils - im Schnittpunkt von $[\mathrm{A}]$ und $[\mathrm{B}]$ wider (die Schenkungen von I 222, die I 223 bestätigt wurden, die ersten elf castra, die ı oo Dörfer und die Eigentümer in den Gegenden von Gruth (Gruta) und dem späteren Kulmsee).

4. Zwischen I 228 und I23 I änderte sich die Situation mit der Ankunft des Deutschen Ordens: Konrad gab ihm das Kulmerland im April 228 (Vertrag von Biecz) und wiederum I 230, ${ }^{87}$ und Christian überließ ihm zuerst den Erlös des Zehnten (3. Mai I 228: Vertrag von Mogiła). Dann:

a. zunächst übergab er I 230 vermutlich in einer bloßen Vorurkunde (keine Spur von Siegel, reduzierte Datierung, kein Protokoll, keine prominenten Zeugen außer dem Abt von Łekno) die erhaltenen und erworbenen Be-

85 Am 30. Juli 1223 übergab er dem Bischof drei weitere Dörfer (Naroschinik, Szarne und Rudky), vgl. Preußisches Urkundenbuch, I.I, hrsg. v. Philippi, 35 Nr. 47. Darüber genehmigte Konrad mindestens drei Handlungen (Schenkungen oder Einkäufe) zugunsten Christians von polnischen Fürsten oder milites: 27. Juli 1223 (Schenkungen vom miles Christian des Dorfes Cossobudo, vgl. ebd., 36 Nr. 49. Im selben Jahr kaufte Christian die Dörfer Razyn (heute Raciniewo) neben Chełmno (Kulm) und Malynino (heute Malinkowo) neben Grudziądz (Graudenz), vgl. Preußisches Urkundenbuch, I.2, hrsg. v. Philippi, $36-37$ Nr. 50; 37-38 Nr. 5 I.

86 Preußisches Urkundenbuch, I.I, hrsg. v. Philippi, 46 Nr. 62. Wahrscheinlich ist der Text von Gregor IX. derselbe als der von Honorius III. Es wäre dennoch interessant zu überprüfen, ob die Liste der 1227 Schenkungen nicht erweitert wurde, was nur die Prüfung der Registri Vaticani ermöglichen würde und was ich noch nicht tun konnte (vgl. Archivio Segreto Vaticano, Reg. Vaticani, Greg. IX, t. I).

87 Preußisches Urkundenbuch, I.I, hrsg. v. Philippi, 47 Nr. 64; 55-56 Nr. 75; $58-60$ Nr. 78 (Kruschwitzer Vertrag). 
sitzungen dem Deutschen Orden im Austausch für die militärische Unterstützung der Ordensbrüder ${ }^{88}$;

b. und I23 I, in einer Urkunde, die alle Merkmale einer echten und endgültigen $^{89}$ Urkunde aufweist, gab er alles auf, was Konrad und der Bischof von Płock ihm gegeben hatten, ebenso den Besitz von Radzyń (Rehden), den er selbst gekauft hatte. Dazu forderte er keine Gegenleistung. Er behielt nur seine bischöflichen Rechte; das Kulmerland ist immer noch ein Teil seiner Diözese Preußen.

5. Während seiner Gefangenschaft unter den Heiden, zwischen I 233 und I 238 , war der Bischof ein Opfer der Gier des Deutschen Ordens und verlor er alle seine Besitzungen im Kulmerland (und auch seine Urkunden), ${ }^{90}$ wie es die Briefe von Gregor IX. zeigen. ${ }^{11}$ Zwischen I 238 und I 240 versuchte er, sie wiederherzustellen, und ließ eine Abschrift der um I 228 erhaltenen Urkunden von seinen Zisterzienser-Verbündeten bestätigen. Er fügte I 2 castra und das Löbauer Land hinzu, von dem er überzeugt war, die Rechte zu haben - was die ordinatio mit dem Orden zwischen Februar I 240 und April I 242 bestätigt. So verdoppelte er die Zahl seiner Befestigungen und verdichtete seine Herrschaft. Gleichzeitig ließ er auch die Zisterzienseräbte von Łekno und Ląd einen zurückdatierten Brief schreiben, der den Vasallenstatus des Ordens festlegt, der eine reine Fiktion war. ${ }^{22}$ Sein Widerstand war vergeblich. Schließlich

88 Berlin, Geheimes Staatsarchiv Preußischer Kulturbesitz, XX. Hauptabteilung, Pergamenturkunden, Schiebl. ı09, Nr. 6 (Ausgabe: Preußisches Urkundenbuch, I.I, hrsg. v. Philippi, 53-54 Nr. 73).

89 Berlin, Geheimes Staatsarchiv Preußischer Kulturbesitz, XX. Hauptabteilung, Pergamenturkunden, Schiebl. 59, Nr. I (Ausgabe: Preußisches Urkundenbuch, I. I, hrsg. v. Philippi, 63 Nr. 82).

90 Grochowski, Chrystian, 97.

91 Brief vom I I. April I 240, in dem der Bischof von Meißen angewiesen wird, die Untersuchung durchzuführen, vgl. Preußisches Urkundenbuch, I. I, hrsg. v. Philippi, , oo- I02 Nr. I 34.

92 Ebd., 54-55 Nr. 74. Die Unterwerfung des Ordens wäre im Widerspruch zu dem Privileg gestanden, das Honorius III. I 2 I 6 gewährt hatte, um ihn von jeder Vasallentums zu befreien (Ingrid Matison, "Die Lehnsexemption des Deutschen Ordens und dessen staatsrechtliche Stellung in Preußen," Deutsches Archiv zur Erforschung des Mittelalters 2 I (1965): I 94-248). Dennoch (und trotz der wahrscheinlichen Erfindungen der beiden Zisterzienseräbten), unterstreicht Maciej Dorna die Wichtigkeit dieses Vertrags von Leslau, um die nachträglichen Beziehungen zwischen dem Bischof und dem Orden zu verstehen, vgl. Maciej Dorna, "Uwagi o interpretacji tzw. układu włocławskiego pomiędzy biskupem Prus Chrystianem a Krzyżakami ze stycznia I 239 roku," Komunikaty Mazursko-Warmińskie 2/280 (2013): I 8 I-202; vgl. auch Gerard Labuda, "Über die Urkunden zur Gründung des Deutschen Ordens im Kulmerlande und in Preußen in den Jahren I 226-I 234," in Die Ritterorden zwischen geistlicher und weltlicher Macht im Mittelalter, Ordines Militares. Colloquia Torunensia Historica V, hrsg. v. Zenon H. Nowak (Toruń: Wydawnictwo Uniwersytetu Mikołaja Kopernika, I990), 2 I-44, besonders 32-33 (Neudr.: Gerard Labuda, Studia krytyczne o poczattach Zakonu Krzyżackiego w Prusach 
warf er das Handtuch, nachdem Preußen durch den Legaten Wilhelm von Modena in vier Diözesen aufgeteilt wurde ${ }^{93}$ und Innozenz IV. Druck auf ihn ausgeübt hatte, sich eines der Bistümer zu wählen (sonst würde er das Bischofsamt verlieren ${ }^{94}$ ), und definitiv verließ er die Region.

6. I 243 teilte Wilhelm von Modena Preußen in vier Diözesen auf.95 Die kulmische Diözese enthielt das Löbauer Land. In jeder dieser Diözesen sollten die Bischöfe ein Drittel des Territoriums und der Deutsche Orden zwei Drittel einnehmen. Diese Verordnung änderte daher die Entscheidungen von Konrad von Masowien und die Zugeständnisse von Christian von Preußen zugunsten des Ordens.

7. I 264 übermittelte wahrscheinlich der gewählte Bischof von Kulm, Friedrich, dem päpstlichen Legaten die Urkunde von I 228 [L'], die in seinem Archiv aufbewahrt wurde. Auf Wunsch der Gebietiger des Ordens wurde der Text aktualisiert, und es wurden veraltete Elemente beseitigt (insbesondere der Titel eines episcopus Prutie). Interessant ist, dass Friedrich von Kulm I 264 auch die Bestätigung von Honorius III. von 1223 durch den Legaten Anselm bestätigen ließ ${ }^{96}$ Außerdem hat der Bischof von Kulm, was T. Jasiński betont, sein Siegel nicht angebracht: es ist also anzunehmen, dass er das Transumpt von Anselm als unwichtig betrachtete, weil das „Original“ in seinem Archiv aufbewahrt blieb - wie T. Jasiński implizit zugibt. Dies unterstützt die Hypothese, dass es eine überarbeitete Version des Vertrags ([L']) gab, die für die Abschrift von 1264 verwendet wurde.

8. Schließlich, handelt es sich um Fälschungen? Wenn wir die Hypothese der Existenz von [L'] akzeptieren, können die Änderungen in [A] entweder als legitim oder betrügerisch betrachtet werden. Die Änderungen in [B] sind offensichtlich bloße Korrekturen oder Aktualisierungen. Obwohl Christian seine Rechte am Kulmerland tatsächlich I 23 I an den Orden übertragen hatte, behielt er dort einige Besitzungen und hatte noch Rechte im Löbauer Land (laut des Vertrags mit dem Orden zwischen April I 240 und April I 242). Es ist daher möglich, dass er 1240 eine frühere Urkunde von I 228 interpolierte, indem er legitime Besitzungen einführte. Kurz gesagt, wäre $[\mathrm{A}]$ keine eigent-

i na Pomorzu (Poznań: Wydawnictwo Poznański, 2007), i 89-2 I I); Marian Dygo, Studia nad początkami wtadztwa zakonu niemieckiego w Prusach (I226-I259) (Warszawa: Uniwersytet Warszawski, 1992), 65 .

93 Preußisches Urkundenbuch, I.I, hrsg. v. Philippi, I 08 - I 09 Nr. I 43 (Urkunde vom 4. Juli I 243).

94 Ebd., I 20 Nr. 159 (Urkunde vom I6. Januar I 245).

95 Ebd., I $08-109$ Nr. I 43; diese Vereinbarung wurde durch Innozenz IV. am 8. Oktober I 243 in einem Brief an Hochmeister Gerhard von Malberg bestätigt, vgl. ebd., I I 5 Nr. I 52.

96 Codex Diplomaticus Regni Poloniae, IV, hrsg. v. Dogiel, 2-3 Nr. II. 
liche Fälschung, sondern sie gehört zur Kategorie der „Kanzleifälschungen“. [B] wurde wahrscheinlich auf der Grundlage derselben Urkunde von 1228 verfasst, und dann in Bezug auf die Entwicklungen der Situation seit I 240 aktualisiert (Ersetzung des preußischen Bischofs durch vier Bischöfe, diverse Abkommen mit den Herzögen von Masowien über das Löbauer Land zwischen I 242 und 1 257, Eintritt des Bischofs von Kulm in den Deutschen Orden).

\section{ANHANG I.}

Identifizierung und Status der Schenkungen in den drei Fassungen

fettgedruckt: die Schenkungen, die sich nicht verändert haben unterstrichen: die Schenkungen, die sich verändert haben kursiv: die Schenkungen, die sich nur in einer Fassung befinden

\begin{tabular}{|c|c|c|c|}
\hline Ort & I 223 & I $238-I 240$ & I264 \\
\hline Kulmerlands Schenkung & $\begin{array}{l}\text { idem dux terram } \\
\text { eandem }[. . .] \\
\text { contulit })\end{array}$ & $\begin{array}{l}\text { partem } \\
\text { territorii } \\
\text { Colmensis }\end{array}$ & $\begin{array}{l}\text { partem } \\
\text { territorii } \\
\text { Colmensis }\end{array}$ \\
\hline Kulm (Chełmno) & castrum & castrum & castrum \\
\hline Graudenz (Grudziądz) & castrum & castrum & castrum \\
\hline Wabsko (Wabcz) (8 km östlich von Chełmno) & castrum & castrum & castrum \\
\hline $\begin{array}{l}\text { Copriven (Pokrzywno) }(8 \mathrm{~km} \text { sudöstlich von } \\
\text { Grudziądz) }\end{array}$ & castrum & castrum & castrum \\
\hline Colno (Kolno) $(7,5 \mathrm{~km}$ nordöstlich von Chełmno) & villa & castrum & castrum \\
\hline $\begin{array}{l}\text { Mirche (Morczyny (?)) (30 km südostlich von } \\
\text { Chełmno) }\end{array}$ & villa & villa & villa \\
\hline $\begin{array}{l}\text { Charnese (Czarże) (I I km nordöstlich von } \\
\text { Bydgoszcz) }\end{array}$ & villa & villa & villa \\
\hline $\begin{array}{l}\text { Bolemino (Bolumin) } \\
\text { (8 km östlich von Bydgoszcz) }\end{array}$ & villa & villa & villa \\
\hline $\begin{array}{l}\underline{\text { Villisaz }}(\text { Wieldzadz) } \\
\text { nordwestlich von Wąbrzeźno) }\end{array}$ & possessio & castrum & $\underline{\text { castrum }}$ \\
\hline Kysin (Gzin) (1 2 km nordöstlich von Bydgoszcz) & possessio & castrum & castrum \\
\hline $\begin{array}{l}\text { Ploth } \\
\text { (9 }(\text { plutowo }) \\
\text { südwestlich von Chełmno) }\end{array}$ & possessio & castrum & $\underline{\text { castrum }}$ \\
\hline $\begin{array}{l}\text { Ruth (Ruda) ( I km südlich von Grudziądz oder } \\
\text { Ruda bei Sarnowo) }\end{array}$ & & castrum & castrum \\
\hline
\end{tabular}


Identifizierung und Status der Schenkungen...

\begin{tabular}{|c|c|c|c|}
\hline Ort & I 223 & I $238-I 240$ & I 264 \\
\hline $\begin{array}{l}\text { Glamboki (Grębocin) (9 } \mathrm{km} \text { nordöstlich von } \\
\text { Toruń) }\end{array}$ & & castrum & castrum \\
\hline Turno (Turzno (?)) & & castrum & castrum \\
\hline Pin (Pień) (4 km nordöstlich von Bydgoszcz) & & castrum & castrum \\
\hline Postolsco/Postolko (?)_unbekannt ${ }^{4}$ ) & & castrum & villa \\
\hline $\begin{array}{l}\text { Kovalevo (Kowalewo) ( } \mathrm{I} 2 \mathrm{~km} \text { nordwestlich von } \\
\text { Golub) }\end{array}$ & & castrum & \\
\hline $\begin{array}{l}\text { Belyz (Bielice) ( } 5 \mathrm{~km} \text { nordwestlich von Nowe } \\
\text { Miasto Lubawskie oder Bielczyny } 3 \mathrm{~km} \text { nördlich von } \\
\text { Chełmża (?)) }\end{array}$ & & castrum & \\
\hline Colman (Chetmoniec) (4 km südlich von Kowalewo) & & castrum & \\
\hline $\begin{array}{l}\text { Ostrovith } \\
\text { Golub) }\end{array}$ & & castrum & $\underline{\text { villa }}$ \\
\hline Nenyr (Niewierz) (7 km südwestlich von Brodnica) & & castrum & \\
\hline $\begin{array}{l}\text { Bobrofh (Bobrowo) (9 } \mathrm{km} \text { nordwestlich von } \\
\text { Brodnica. }\end{array}$ & & castrum & \\
\hline $\begin{array}{l}\text { Wanzino (Wadzyń) (I } 2 \mathrm{~km} \text { nordwestlich von } \\
\text { Brodnica) }\end{array}$ & & castrum & \\
\hline $\begin{array}{l}\text { Mylesevo (Mileszewy) ( } 16 \mathrm{~km} \text { nordwestlich von } \\
\text { Brodnica) }\end{array}$ & & castrum & \\
\hline $\begin{array}{l}\text { Osechino (Osieczek (?)) (l I } \mathrm{km} \text { östlich von } \\
\text { Wąbrzeźno) }\end{array}$ & & castrum & \\
\hline Plovenzo (Ptowęż) (I $5 \mathrm{~km}$ südlich von Łasin) & & castrum & \\
\hline Jablovo (Jabtonowo) ( 44 km östlich von Radzyń) & & castrum & \\
\hline Gruth-Wald und bezügliche Dörfer & & $\begin{array}{l}\text { silva Gruth, } \\
\text { villas }\end{array}$ & $\begin{array}{l}\text { silva Gruth, } \\
\text { villas }\end{array}$ \\
\hline Güter in der Umgebung von Loza & & hereditates & bereditates \\
\hline ı o० Dörfer und erbliche Güter von Herzog Konrad & & $\begin{array}{l}\text { villae, } \\
\text { possessiones, } \\
\text { hereditates ( } 28 \\
\text { angegeben) }\end{array}$ & $\begin{array}{l}\text { villae, } \\
\text { possessiones, } \\
\text { hereditates }(32 \\
\text { angegeben) }\end{array}$ \\
\hline
\end{tabular}




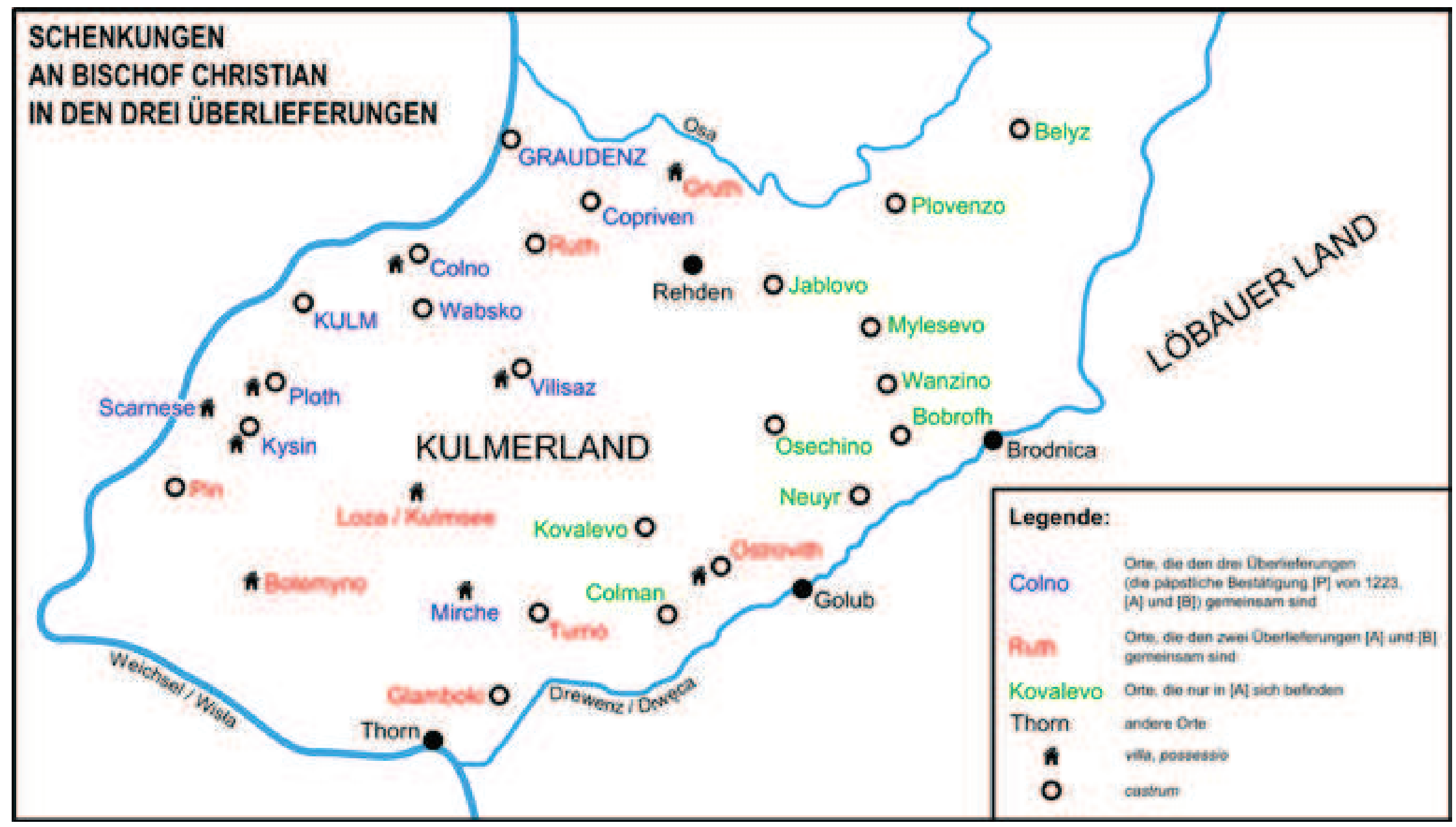

Karte: Schenkungen an Bischof Christian in den drei Überlieferungen. 
L: Original (verschwunden) 1222

P: päpstliche Bestätigung 1223

L' : erneuerte und interpolierte Fassung 1228 (wahrscheinlich)

A: Vidimus von $1238-1240$

B: Vidimus von 1264

L 1222

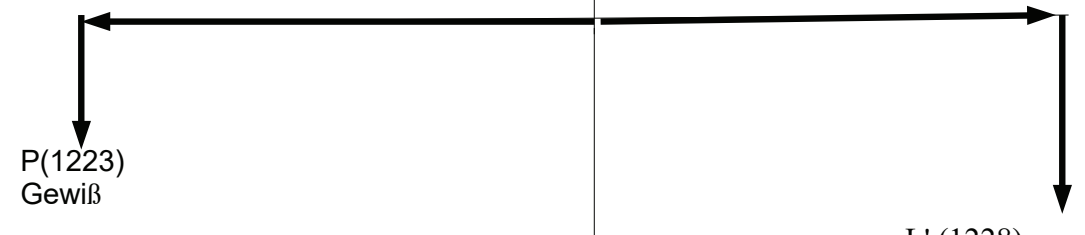

A (1240)

$A=(L+x)$

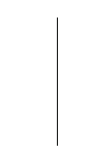

$\mathrm{B}(1264)=(\mathrm{A}-\mathrm{y})$

Hypothese 2
L' (1228)

Hypothese 1

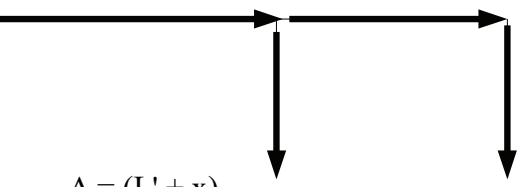

$\mathrm{A}=\left(\mathrm{L}^{\prime}+\mathrm{x}\right)$

Hypothese 1a

$\mathrm{B} \approx \mathrm{L}^{\prime}$

Hypothese 1b

Sicher oder sehr wahrscheinliche Hypothesen

Stemma der Handschriften 


\section{PRIMARY SOURCES:}

Berlin. Geheimes Staatsarchiv Preusischer Kulturbesitz, XX. Hauptabteilung, Pergamenturkunden, Schiebl. Culmer Diözesan Archiv, Nr. I.

Berlin. Geheimes Staatsarchiv Preußischer Kulturbesitz, XX. Hauptabteilung, Pergamenturkunden, Schiebl. 59, Nr. I.

Berlin. Geheimes Staatsarchiv Preußischer Kulturbesitz, XX. Hauptabteilung, Pergamenturkunden, Schiebl. ı 99, Nrn. 6, 25.

"Franciscani Thorunensis Annales Prussici (94I-1410)." Herausgegeben von Ernst Strehlke. In Scriptores rerum Prussicarum. Die Geschichtsquellen der preußischen Vorzeit bis zum Untergange der Ordensherrschaft. Bd. III, herausgegeben von Theodor Hirsch, Max Toeppen und Ernst Strehlke, 57-3 I6. Leipzig: S. Hirzel Verlag, i 866 (Nachdruck: London: Forgotten Books, 20 I 8).

Codex diplomaticus et commerationum Masoviae generalis / Zbiór ogólny przywilejów i spominków mazowieckich. Bd. I. Obejmujący materyat do zgonu Konrada I. Herausgegeben von Jan K. Kochanowski. Warszawa: Wł. Łazarskiego, I 9 I 9.

Codex diplomaticus. Oder Ubrkunden, So die Pommersch-Rügianisch-und Caminische, auch andere benachbarte Lande angehen. Aus lauter Originalien oder doch archivischen Abschrifften in chronologischer Ordnung zusammen getragen, und mit einigen Anmerckungen erläutert. T. I. bis I 269 incl. Herausgegeben von Friedrich von Dreger. Stettin: Johann Friderich Spiegel, i 748.

Codex Diplomaticus Regni Poloniae et Magni Ducatus Lithuaniae. T. IV. In quo totius Prussiae Res continentur. Herausgegeben von Maciej Dogiel. Vilnae: Typographia Regia \& Reipub[lice] CC. RR. Scholarum Piarum / Regimonti-Lipsiae: Officina Libraria Johannis Jacobi Kanteri, 1764.

Petrus de Dusburgk. Chronicon terrae Prussiae. Herausgegeben von Jarosław Wenta und Sławomir Wyszomirski. Monumenta Poloniae Historica. nova series XIII. Kraków: Polska Akademia Umiejętności, 2007.

Preußisches Urkundenbuch. Politische (allgemeine) Abteilung. Bd. I. Die Bildung des Ordensstaats, Hälfte I. Herausgegeben von Rudolf Philippi in Verbindung mit [Carl P.] Woelky. Königsber/Pr.: Hartungsche Verlagsdruckerei, I 882 (Nachdruck: Sidney: Wentworth Press, 20 I 8 ).

Preußisches Urkundenbuch. Politische (allgemeine) Abteilung. Bd. I. Die Bildung des Ordensstaats, Hälfte 2. Bearbeitet von August Seraphin. Königsberg/Pr.: Hartungsche Verlagsdrückerei, I 909.

Preußisches Urkundenbuch. Bd. III, Lief. I. I335-I34I. Herausgegeben von Max Hein. Königsberg/Pr.: Gräfe und Unzer, I 944.

Schlesisches Urkundenbuch. Bd. II, 2. Lieferung. I2I7-I230. Herausgegeben von der Historischen Kommission für Schlesien, bearbeitet von Heinrich Appelt. WienKöln-Graz: Verlag Hermann Böhlaus Nachf., I 968. 
Tabulae ordinis Teuthonici ex tabularii regii Berolinensis codice potissimum. Herausgegeben von Ernst Strehlke. Berlin: Weidmann, i 869 (Nachdruck: herausgegeben von HansEberhard Mayer. Toronto: Toronto University Press, I 975).

Urkundenbuch des Bisthums Culm. Theil I. Das Bisthum Culm unter dem Deutschen Orden I243-1466. Herausgegeben von Carl P. Woelky, Neues Preussisches Urkundenbuch. Westpreussischer Theil, II. Abtheilung, Urkunden der Bisthümer, Kirchen und Klöster I. Danzig: Commissionsverlag von Theodor Bertling, i 885 (Nachdruck: Lexington: Ulan Press, 2012 ).

Urkundenbuch des Bisthums Culm. Theil II. Das Bisthum Culm unter Polen I466-I774. Herausgegeben von Carl P. Woelky, Neues Preussisches Urkundenbuch. Westpreussischer Theil, II. Abtheilung, Urkunden der Bisthümer, Kirchen und Klöster I. Danzig: Commissionsverlag von Theodor Bertling, i 887 (Nachdruck: Lexington: Ulan Press, 2012).

Vetera monumenta Poloniae et Lithuaniae gentiumque finitimarum historiam illustrantia: maximam partem nondum edita ex tabularis Vaticanis deprompta collecta ac serie chronologica disposita. Bd. I. Ab Honorio PP. III. usque ad Gregorium PP. XII. I217-I409. Herausgegeben von Augustin Theiner. Romae: Typis Vaticanis, I 860 (Nachdruck: Osnabrück: Otto Zeller, i 969).

Woelky, Carl Peter. "Der Katalog der Bischöfe von Kulm," Zeitschrift für Geschichte und Altertumskunde des Ermlands 6 ( I 875-I 876 [ I 877]):383-388 (Quellenedition, Catalogus Episcoporum Culmensium).

Stronczyński, Kazimierz. Wzory pism dawnych w przerysach wystawione, i objaśnione drukowanem i wyczytaniem. Tl. I. Obejmujaca pismo dyplomatów od roku I228 do I536. Warszawa: Kommissyi Rządowej Sprawiedliwości, I 839.

\section{SECONDARY SOURCES:}

Dorna, Maciej. "Uwagi o interpretacji tzw. układu włocławskiego pomiędzy biskupem Prus Chrystianem a Krzyżakami ze stycznia I 239 roku." Komunikaty Mazursko-Warmińskie 2/280 (2013): I 8 I -202.

Grochowski, Paweł. Chrystian. Biskup Prus I2I6-I245 i misja pruska jego czasów. Górna Grupa: Wydawnictwo Verbinum, 20 I 8.

Heym, Wilhelm. "Frühe Burgen des Kulmerlands. Ein Beitrag zu den Burgen, die im Vertrag von Lonyz I 222 »quondam castrum « genannt werden.” Jahrbuch AlbertUniversität zu Königsberg/Pr. I 3 ( 1963 ): 307-320.

Janowski, Andrzej. "Quondam castrum Ruth - próba lokalizacji średniowiecznego grodu w ziemi chełmińskiej w świetle źródeł pisanych i archeologicznych.” Archaeologia Historica Polona $\mathrm{I} 7$ (2007): 277-292.

Jasiński, Tomasz. "Okoliczności nadania ziemi chełmińskiej Krzyżakom w I 228 roku w świetle dokumentu łowickiego.” In Balticum. Studia z dziejów polityki, gospodarki i kultury XII-XVII wieku ofiarowane Marianowi Biskupowi w siedemdziesiata rocznice urodzin, herausgegeben von Zenon H. Nowak, i s I-163. Toruń: Towarzystwo Naukowe w Toruniu, 992 (deutsche Übersetzung: "Die Verleihung des Kulmerlandes an den Deutschen Orden im Jahre 1228 im Licht des Vertrags von Lonyz ( 1222 ).” In To- 
masz Jasiński, Kruschwitz, Rimini und die Grundlagen des preussischen Ordenslandes: Urkundenstudien zur Frühzeit des Deutschen Ordens im Ostseeraum, I-20. Quellen und Studien zur Geschichte des Deutschen Ordens 63, Veröffentlichungen der Internationalen Historischen Kommission zur Erforschung des Deutschen Ordens 8. Marburg: N. G. Elwert Verlag, 2008).

Kętrzyński, Wojciech. Der deutsche Orden und Konrad von Masovien I225-I235. Lemberg: Subrynowicz und Schmidt, I 904.

Labuda, Gerard. "Powstanie i rozwój państwa krzyżackiego w Prusach.” In Gerard Labuda und Marian Biskup. Dzieje Zakonu Krzyżackiego w Prusach. Gospodarka - Spoteczeństwo - Państwo - Ideologia, 96-283. Gdansk: Wydawnictwo Morskie, I 986 (deutsche Übersetzung: "Entstehung und Entwicklung des Deutschordensstaates in Preußen." In Gerard Labuda und Marian Biskup. Die Geschichte des Deutschen Ordens in Preußen: Wirtschaft, Gesellschaft, Staat, Ideologie, übersetzt von Jürgen Heyde und Ulrich Kodur, i I 5-290. Osnabrück: fibre Verlag, 2000).

Liek, Gustav. Die Stadt Löbau in Westpreussen, mit Berücksichtigung des Landes Löbau. Marienwerder: Im Verlage des historischen Vereins, I 892.

Löwener, Marc. Die Einrichtung von Verwaltungsstrukturen in Preussen durch den Deutschen Orden bis zur Mitte des 13. Jahrhunderts. Deutsches Historisches Institut Warschau. Quellen und Studien 7. Wiesbaden: Harrassowitz Verlag, I 998.

Matison, Ingrid. "Die Lehnsexemption des Deutschen Ordens und dessen staatsrechtliche Stellung in Preussen." Deutsches Archiv zur Erforschung des Mittelalters 2 I ( 965 ): I $94-248$.

Miernik, Piotr, "Quondam castrum Pin w świetle najnowszych badań archeologicznych." Archaeologia Historica Polona 22 (2014): 69-87 (http://dx.doi.org/I0.12775/ AHP.20 I 4.004).

Perlbach, Max. Preussisch-polnische Studien zur Geschichte des Mittelalters. Bd. I. Zur Kritik der ältesten preussischen Urkunden. Halle: Max Niemeyer, I 886 (Nachdruck: Wrocław: Elibron Classics, 2006).

Powierski, Jan. "Studia nad strukturą administracyjno-terytorialną ziemi chełmińskiej i michałowskiej w okresie piastowskim." Bydgoskie Towarzystwo Naukowe. Prace wydziatu nauk humanistycznych, ser. C, I 3 (1973): 3-86.

Stownik historyczno-geograficzny ziemi chetminskiej w średniowieczu. Bearbeitet von Krystyna Porębska, unter Mitarbeit von Maksymiliana Grzegorza, redigiert von Marian Biskup. Słownik historyczno-geograficzny ziem polskich w średniowieczu I. Wrocław-Warszawa-Kraków-Gdańsk: Zakład Narodowy im. Ossolińskich, I 97 I (elektronische Edition: http://www.slownik.ihpan.edu.pl/browse.php?d=2 (Chełmno), redigiert von Tomasz Jurek, zugegriffen am 5. Juli 20 I 9).

Torbus, Tomasz. Die Konventsburgen im Deutschordensland Preußen. Schriften des Bundesinstituts für ostdeutsche Kultur und Geschichte i I. München: R. Oldenbourg, I 998.

Voigt, Johannes. Geschichte Preußens von den ältesten Zeiten bis zum Untergange der Herrschaft des Deutschen Ordens. Bd. I. Die Zeit des Heidentums. Königsberg: Verlag der Gebrüder Bornträger, I 827; Bd III. Die Zeit vom Frieden I249 bis zur Unterwerfung der Preußen I283. Königsberg: Verlag der Gebrüder Bornträger, I 828. 